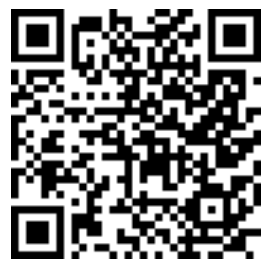

$\bar{I} Q \bar{A} N$-Vol: 02, Issue: 04, Jun-2020

DOI: 10.36755/iqan.v2i04.148 PP: 01-20

OPEN ACCESS

$\bar{I} Q \bar{A} N$

pISSN: 2617-3336

eISSN: 2617-3700

www.iqan.com.pk

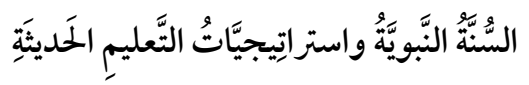

\title{
Al-sunnah al-nabawia and the modern strategies of education
}

\author{
*Dr. Kamal al-Fattouh \\ Assistant Professor, Ilahiyat Faculty, \\ Karabuk University, Karabuk, Turkey. \\ VERSION OF RECORD \\ Received: 20-Jan-20 Accepted: 01-Jun-20 \\ Online/Print: 30-Jun-20
}

\begin{abstract}
Education is the basic key to know about universe and for praciting in our lives. Islam and every other religion amphasizes on seeking the knowledge for our lives, livilihoods, to improve concepts and believes as well as practice on our religions. There are many modern techniques in the education systems around the world under bloom texanomy and also sub techniques like cooperative learning, problem based learning, thinking based learning, competency based learning etc. Even though the diversity of teaching strategies or modern teaching methods, the prophetic narations contained many of these strategies and methods of education. Holy prophet (pbuh) has guided in many of hadiths to diversify educational methods as required by the situation, despite of the description of these methods of education as modern strategies, it is mainly derived from the Sunnah either through the command of the prophet (pbuh) or practical application in the education of his companians. In this regard, by adopting narrative and analytical methodologies, author has identified the foundation of modern techniques and satratigies to educatate ourselves. In this paper, Atuhor finds put many examples of these strategies and shows their pracital forms applied by holy Prophet to educate his companions.
\end{abstract}

Key words: Strategies, Sunnah, Teaching, Modren Techniques, Education, Bloom Taxanomy. 


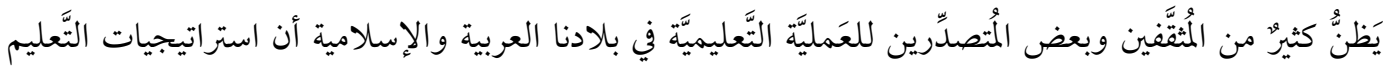

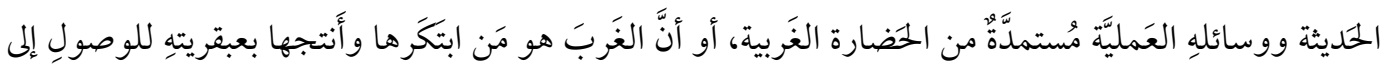

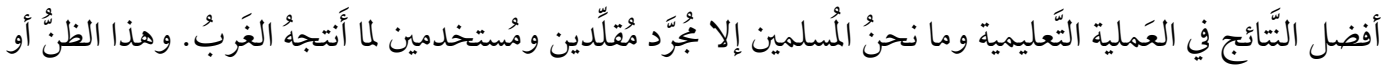

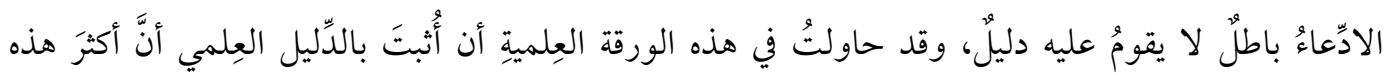

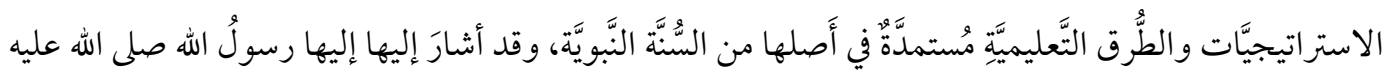

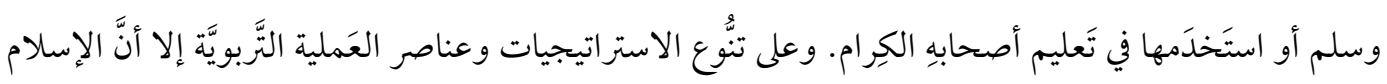

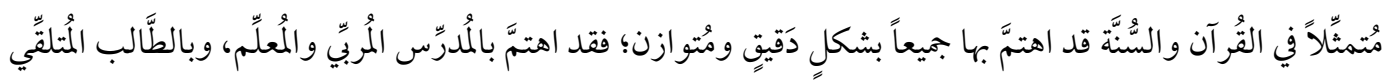

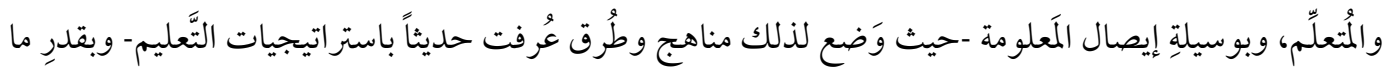

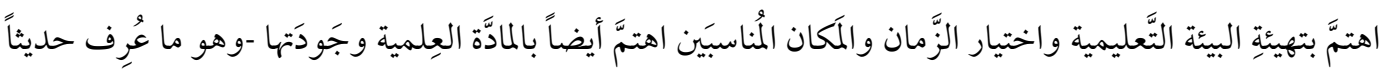

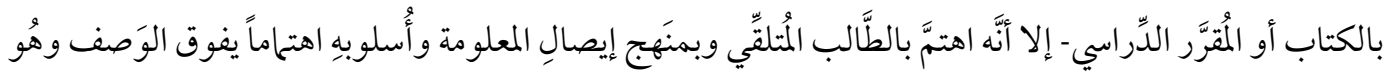

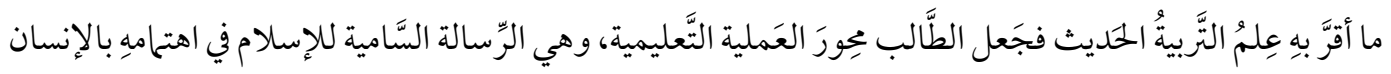

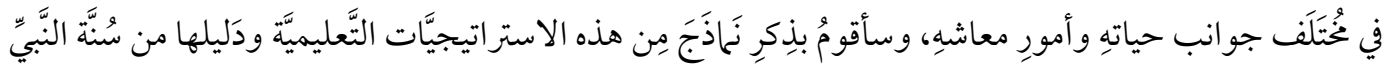

$$
\begin{aligned}
& \text { وطريقِة استخدامِِ ها في تَعليم أصحابه. } \\
& \text { ترابُطُ مَفهومي التَّبّية والتَّعليم: }
\end{aligned}
$$

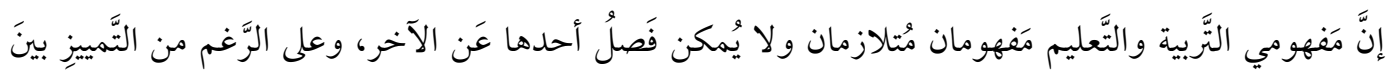

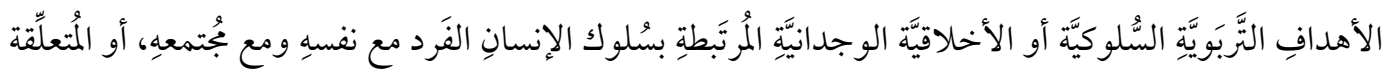

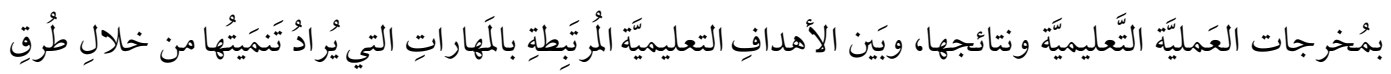

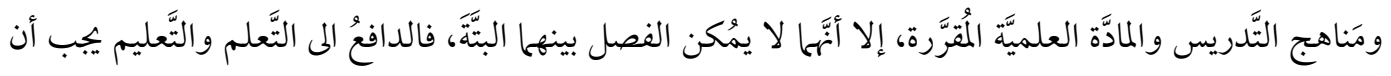

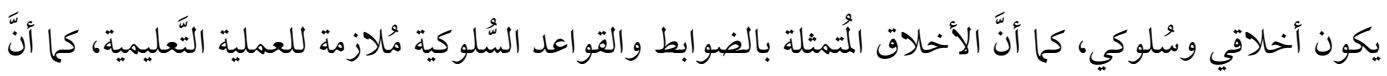

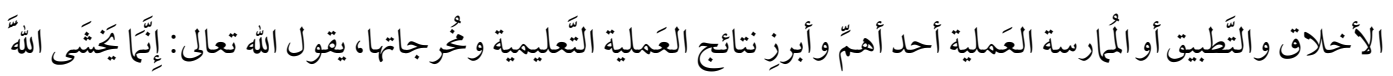




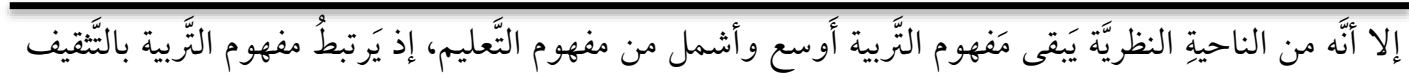

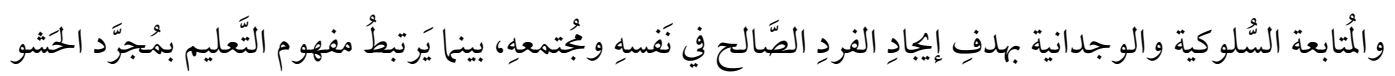

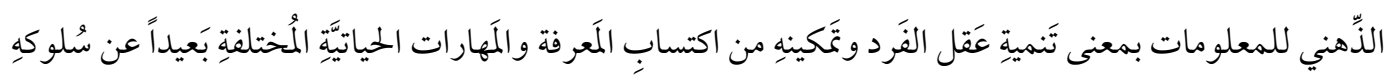

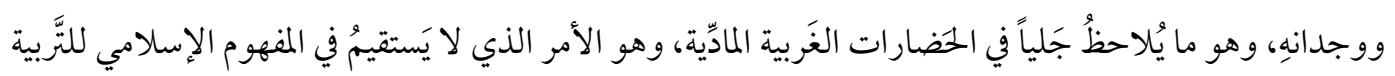
و التَّعليم وهو ما أسميتهُ في مقالٍ بالعِلم الشيطاني إذ الفرقُ بينه وبينَ العِلم الرَّماني هو المُمارسةُ والسُّلوك و التَّطبيق'.

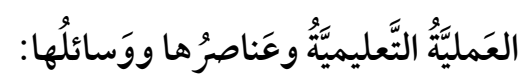

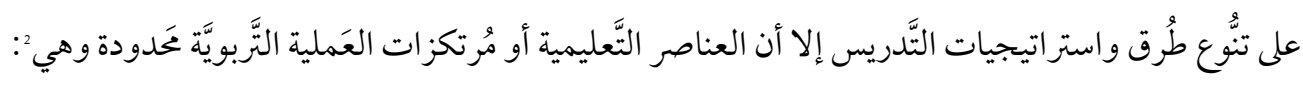
1- مُعلِّم أو مُدرِّس أو مُلقي أو مُلقِّن -وذلك حَسبَ النَّظرة التقليدية للتَّعليم- أو مُدير ومُوجِّه للعَملية التَّعليمية

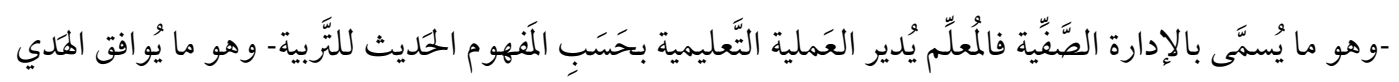
النَّوي في التَّبية والتَّعليم.

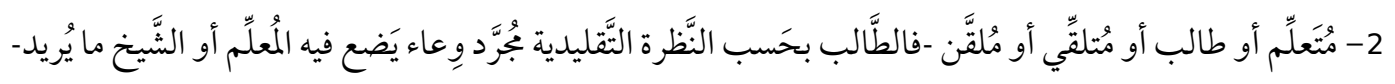

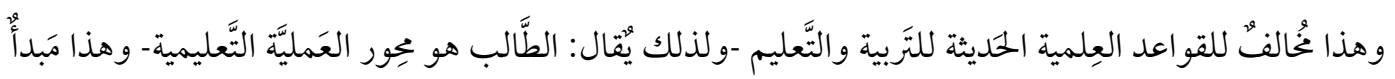
عِلمي حَديث يُو افقُ السُنَّة والمَنْهَجَ النَّبَوي في التََّّبية و التَّعليم.

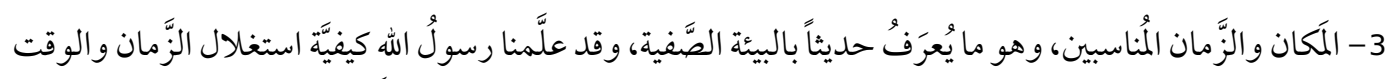
المُناسبين في إيصال المعلومة والتأثير الوجداني.

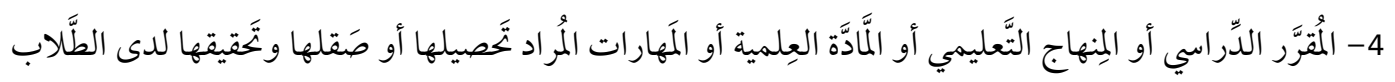
سواء أكانت مَهارات نظرية أو عَملية. 5- استراتيجيات وطُرق أو مَناهج وأساليب ووسائل نظريَّة أو مادِيَّة من أجل تَنفيذ هذه الاستراتيجيات وإيصال

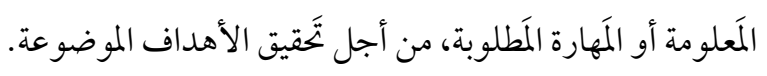
بالإضافة إلى عناصر مُساعِدة مادِّة أو مالية وإدارية واهتحام الدَّولة وعنايتها بالعَملية التَّبوبَّة، وعلى أهمية جميع هذه 1 الفَتُّح، كمال و عبد الرؤف ظَفر، السيرة النَّبية وواقع المسلمين، المجلَّة الباكستانية للبحوث الإسلامية 7 رقم.2 (2011ء)،

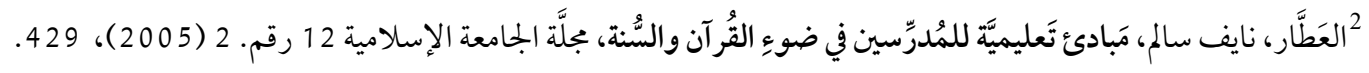




\section{السُنّْة النَّبَّيَّةُ واستراتِيجِيَّاتُ التَّعليم الحَديثَةِ}

العناصر - إذ أنَّ العَملية التَّعليمية عَمليَّة مُتكامِلة كتكامُل ِرسالةِ الدِّين الحنيف ومَصادِرِهِ ومَبادئه- إلا أنَّأهم رَكيزة أو عُنصر من عَناصر التَّعليم هو الطَّالب؛ إذ يُمكن لهُ أن يتعلَّم أو يَصقل مَهاراته من غير مُعلِّم إذا تَوفَّرت له الآليات

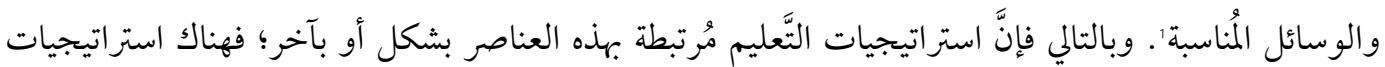

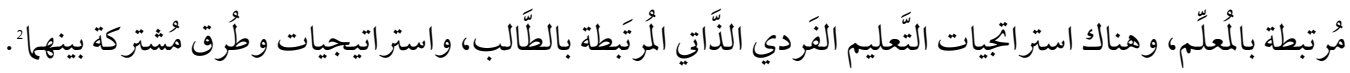
الاستراتيجيَّات والوَسائل التَّعليميَّة:

ونَعني بها: الطُّرق والوَسائل الحديثة في إيصال المَعلومات وتَنمية المَهارات اللازمة، والتَّو اصل بين المُعلِّم والطَّالب بأفضل طريقة وأيسر أُسلوب، للوُصول إلى أفضلِل النَّائج، أما الاستراتيجية فهي فنِّ من فُنون القيادة والإدارة بقصد

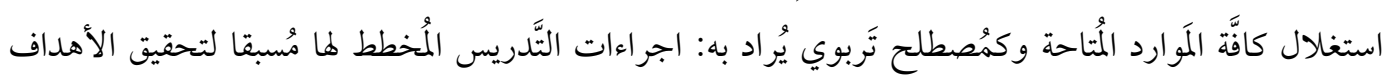

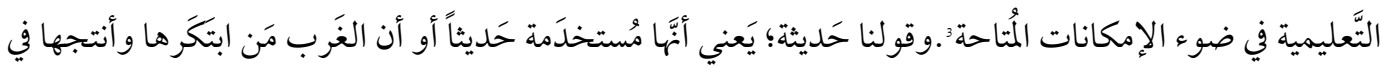

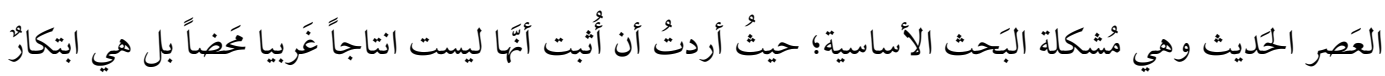

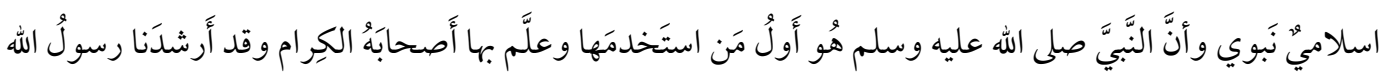

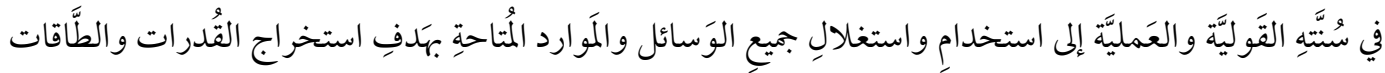
الكامنة وتَنمية كافَّة المهارات العِلمية والعَملية والوجدانية والسُّلوكية وصَقِلِهاء.

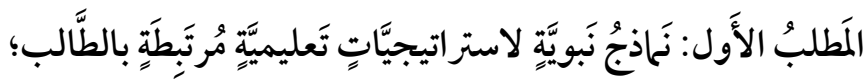
الأول: التَّطيقُ العَمليٌّ للمَبدأ التَّبوي؛ الطَّالب مِوَرَ العَملية التَّعليمية:

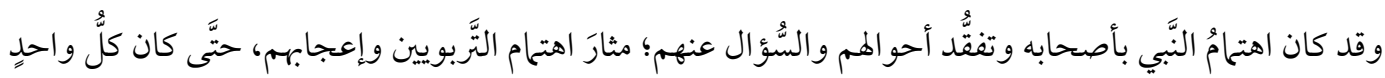

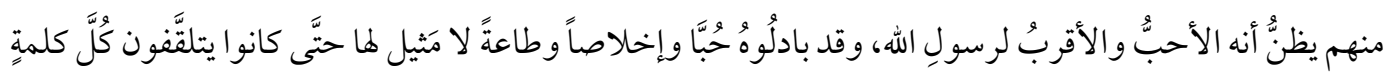

1انيف سالم العَطَّار، مَبادئ تَعليميَّة للمُدرِّسين، 431.

2 شاهين، عبد الحميد، استراتيجيَّات التَّدريس المُتُقدّمة واستراتيجيات التعلُّم، 12.

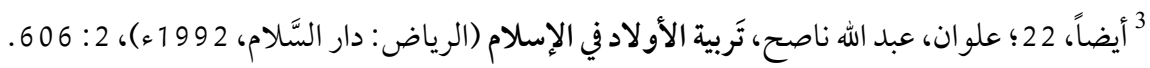

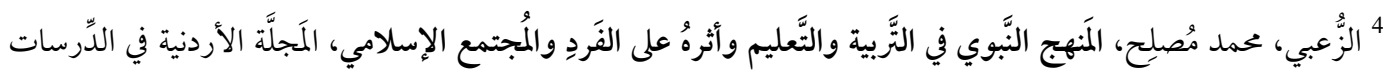

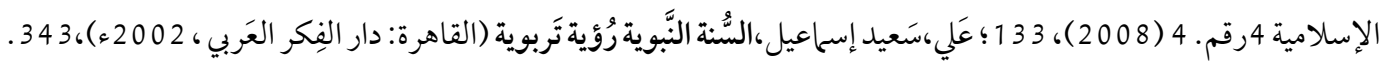




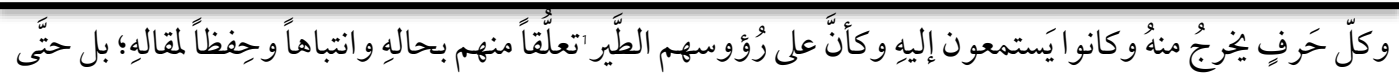

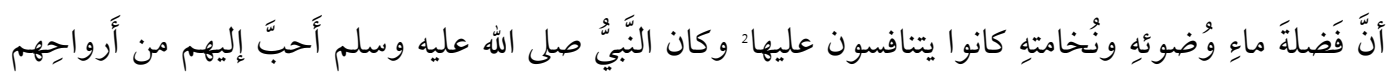

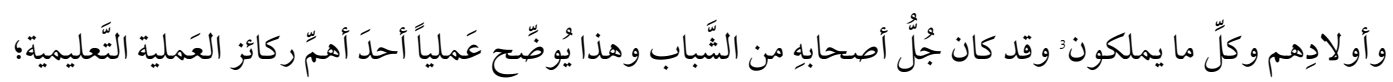
وهي أنَّ الطالب مِور العَلمية التَّبوية.

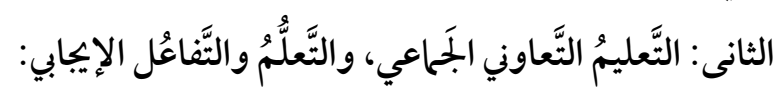

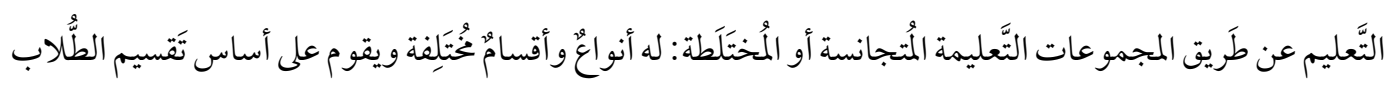

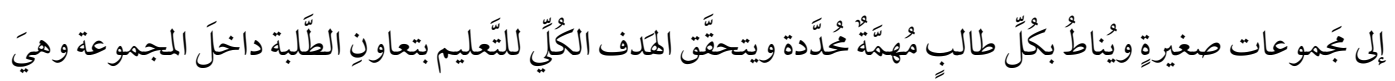

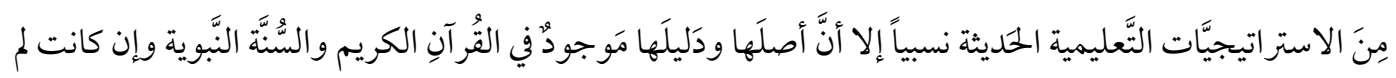

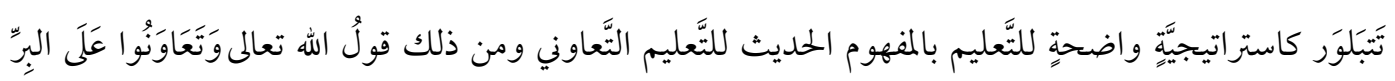

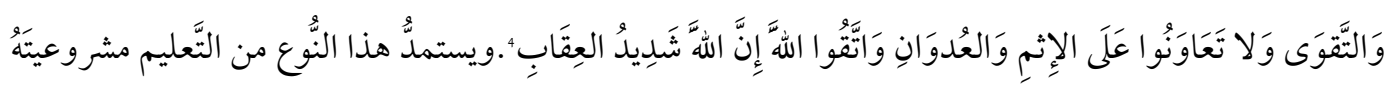

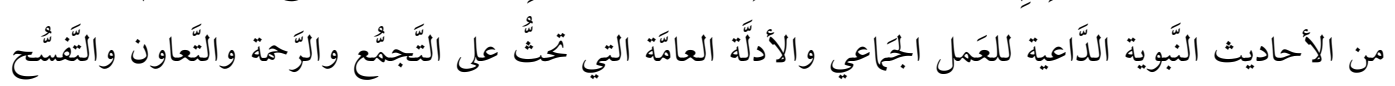

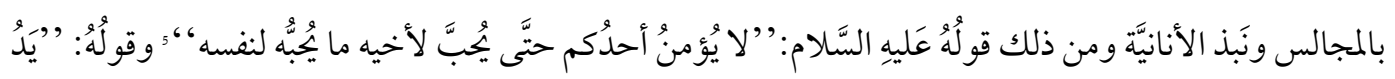

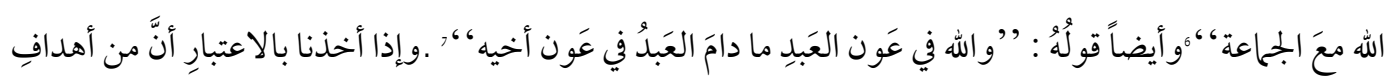

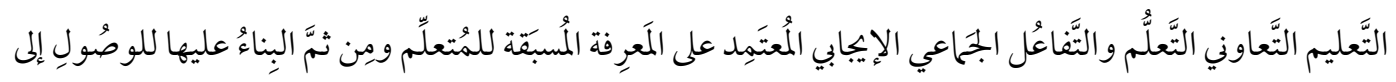

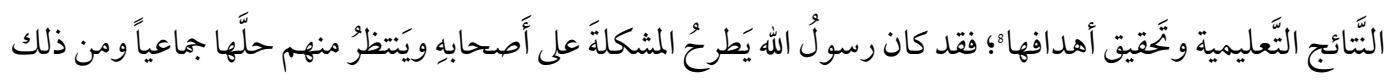

1أبوداؤد، سليهان بن أشعث، السُنن (الرياض: دار السلام، 1999ء)، حديث: 3855.

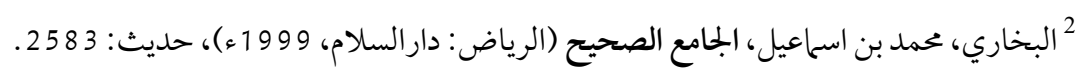

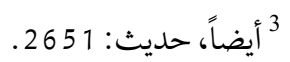
| 'البخاري، الجامع الصَحيح، حديث: 13.

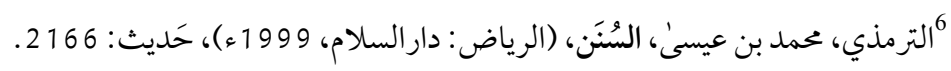

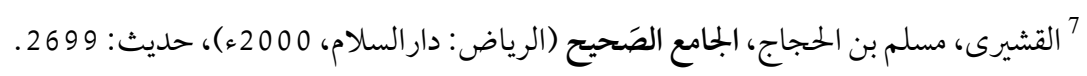
8 خالد مطهر ، دَليل طَرَائق التدريس، 30. 


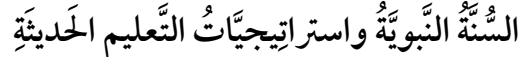

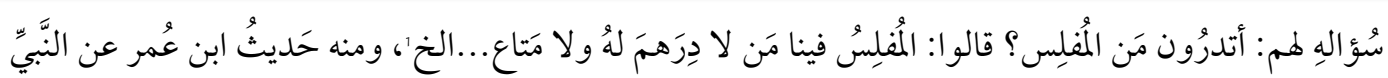

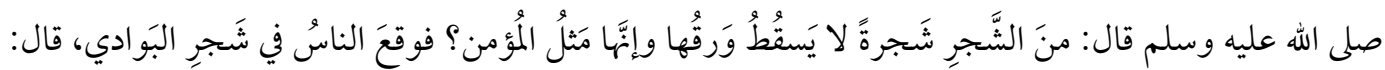

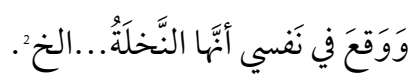

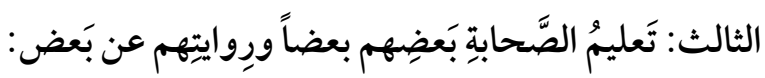

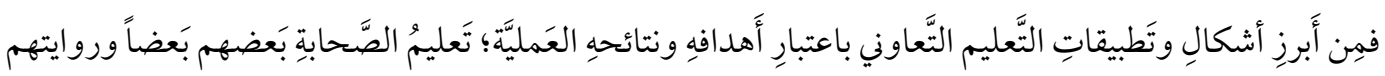

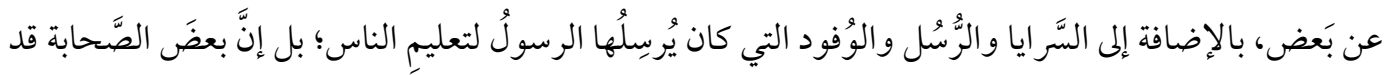

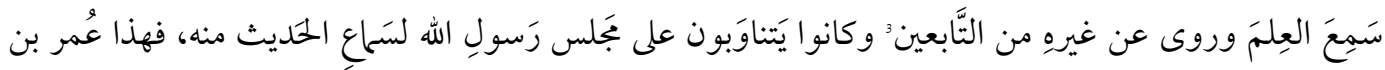

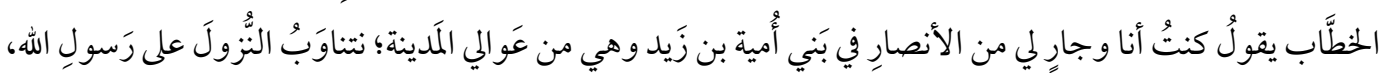

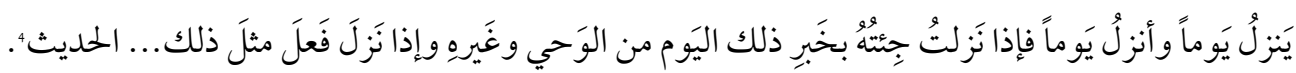

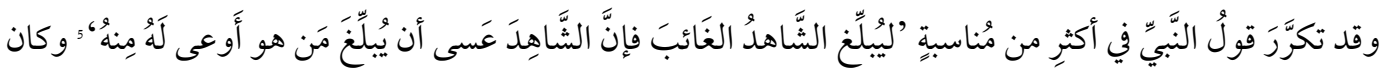

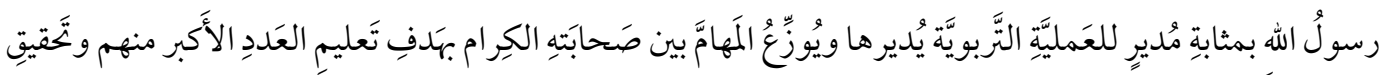

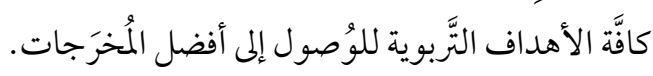

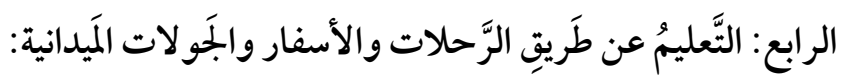

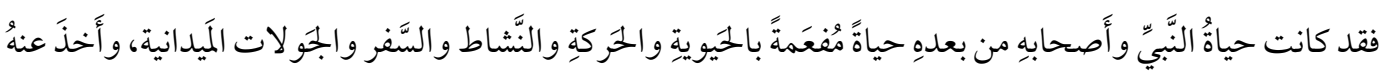

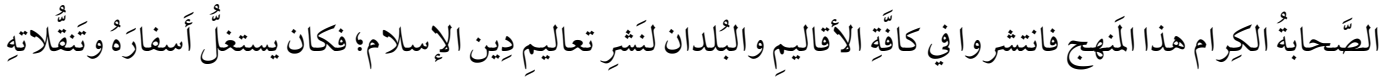

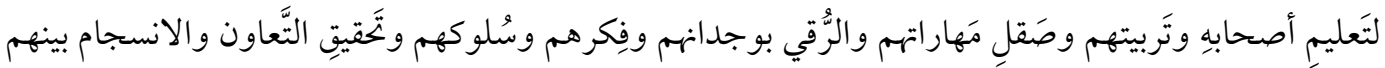

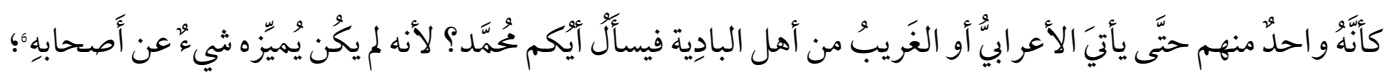

$$
\begin{aligned}
& \text { 1 مسلم، الجحامع الصَحيح، حَديث: } 2581 . \\
& \text { 22 البخاري، الجحامع الصَحيح، الأحاديث: } 61 .
\end{aligned}
$$

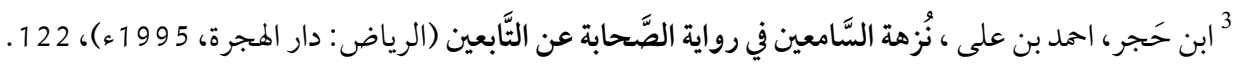

$$
\text { 4البخاري، الجامع الصَحيح ،حديث: } 89 .
$$

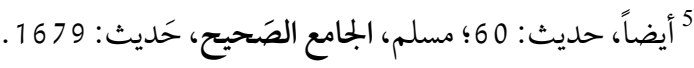

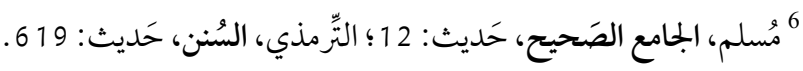




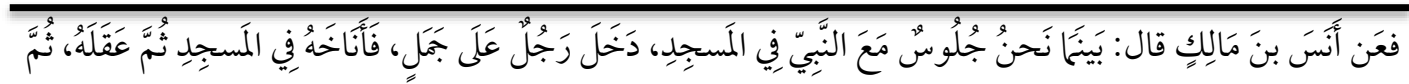

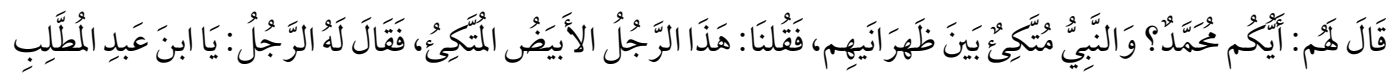

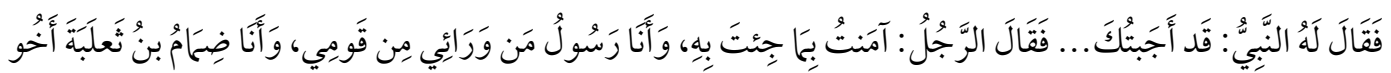

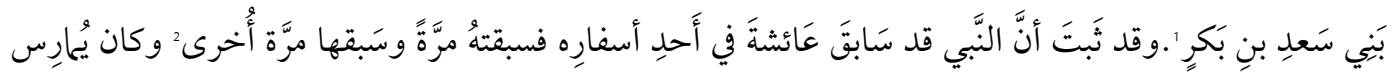

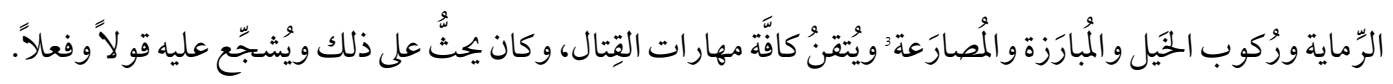
الخامس: إتاحَةُ الفُرصة للمُتعلِّم والاهتحام بكافَّة المُتُعلِّمين:

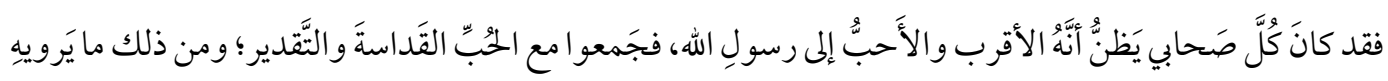

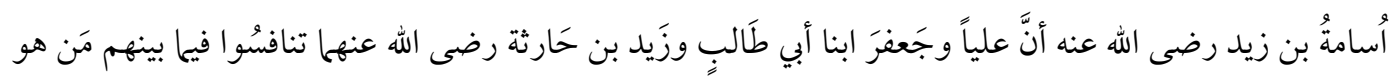

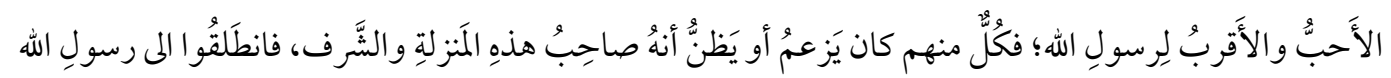

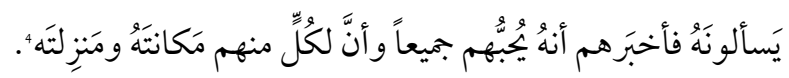

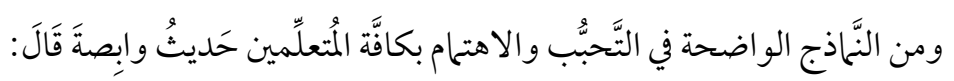

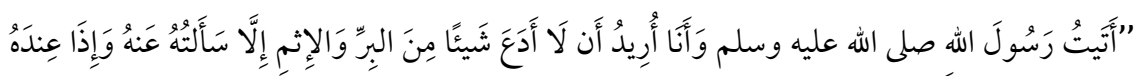

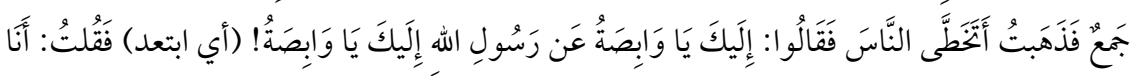

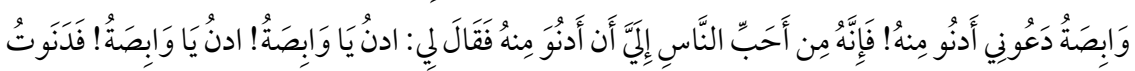

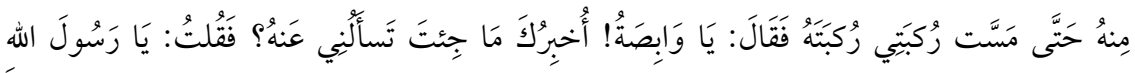

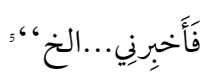

ومن ذلك الحفاوَةُ والتَّرحيبُ عند اللقاء وحُسنُ الاستقبال والاهتحامُ بأسئلِة المُعْلِّمين والإجابة عليها وعَدَمَ

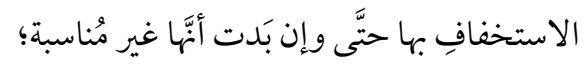

$$
\begin{aligned}
& \text { 1' البخاري، البحامع الصَحيح، حَديث: } 63 .
\end{aligned}
$$

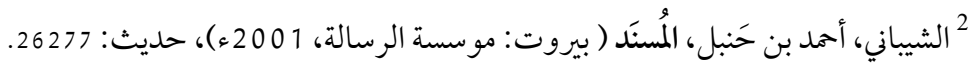

$$
\begin{aligned}
& \text { ألتِّمذي، السُنن، حديث: } 1784 .
\end{aligned}
$$

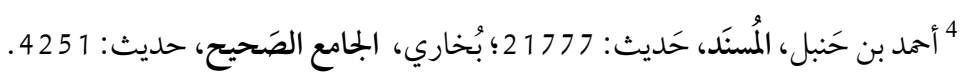

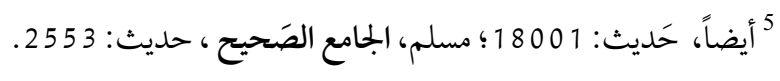




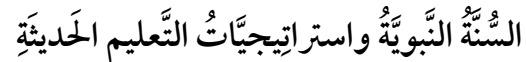

ومِن ذلك سُؤالُ الأَعرابي متى السَّاعة' فَقََالَ رسولُ الله:

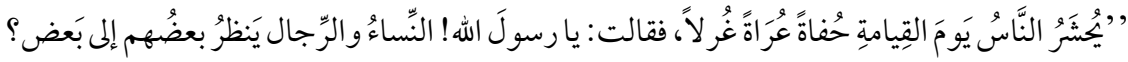

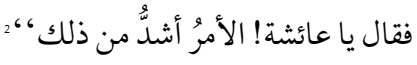

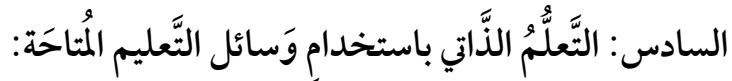

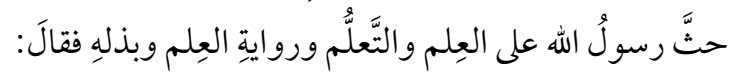

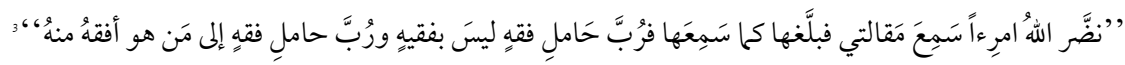

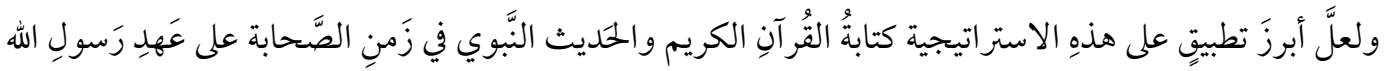

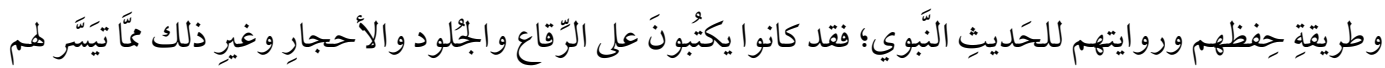

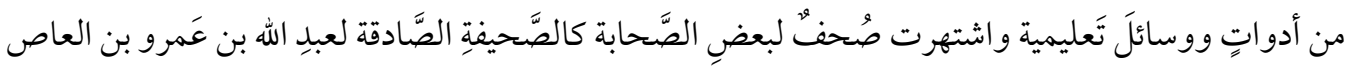

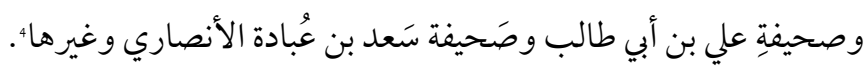

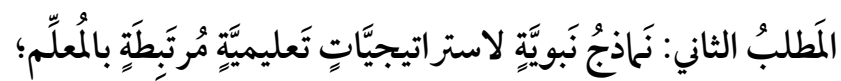

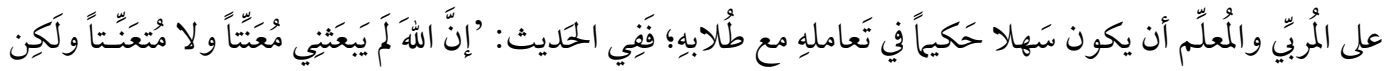

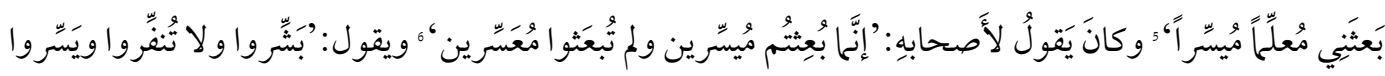

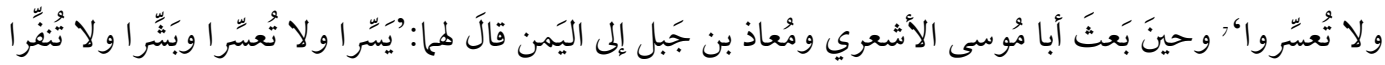

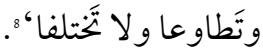

1 البخاري، الجامع الصَحيح، حديث:

2 أيضاً، حديث: 6527؛ كُسلم، الجامع الصَحيح، حَديث: 2859. 33 القزوينى، محمد بن يزيد بن ماجه، السُنن ( الرياض: دار السلام، 1999ء)، حديث، حديث: 230.

4 البخاري، الجامع الصَحيح، حديث: 11 11؛ مُسلم، الجامع الصَحيح، حديث: 1370. 5 مسلم، الجامع الصَحيح ، حَديث: 1478. 6 البخاري، الجامع الصَحيح، حديث: 220. 7 مسلم، الجامع الصَحيح ، حَديث: 1732. 8 البخاري، الجحامع الصَحيح، حديث: 838 30 مسلم، الجامع الصَحيح ، حَديث: 1733 ، 17. 
إيقان: المجلد: 02 ، العدد:04 ، يونيو 2020ء

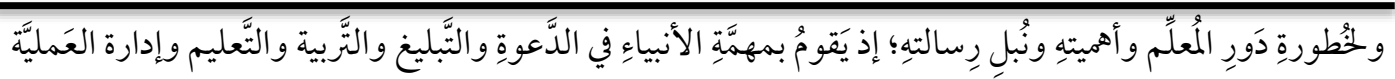

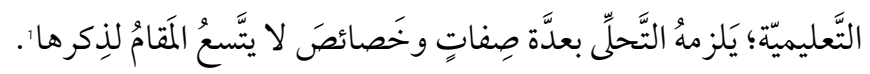
الأول: مُر اعاةُ الفُروق الفَرديَّة في التَّعليم:

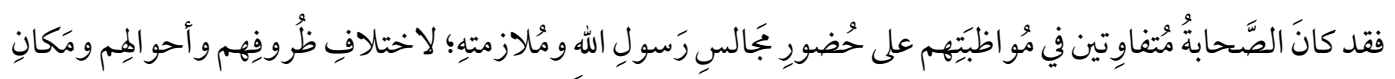

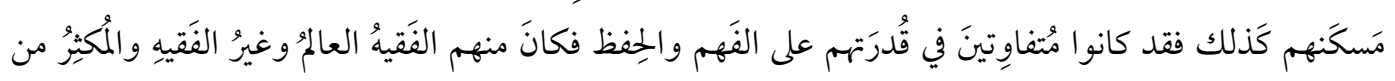

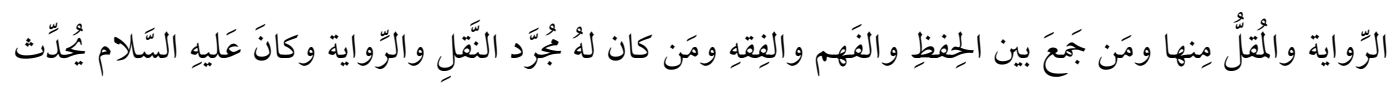

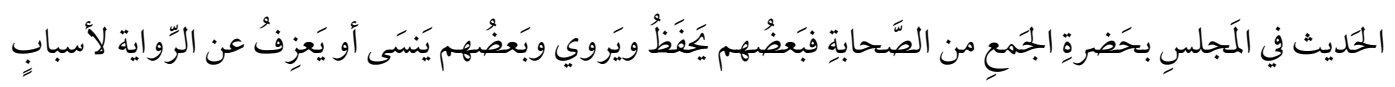

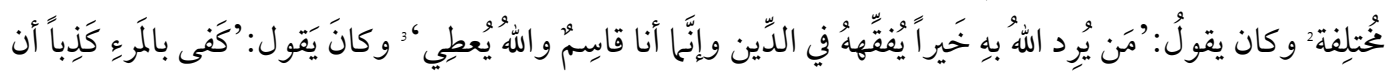

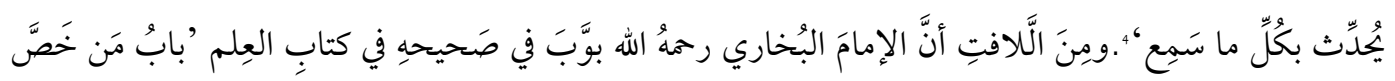

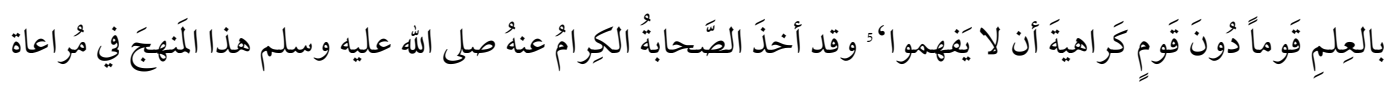

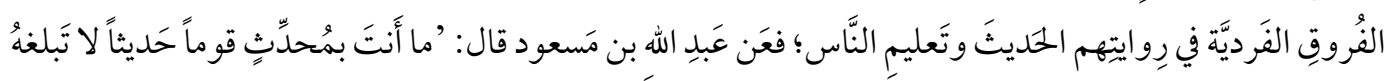

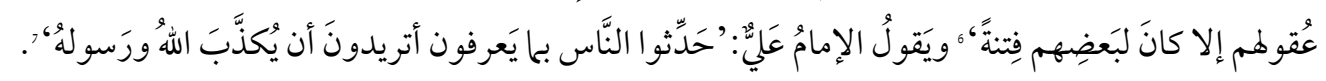
الثانى: التَّحبُّبُو والمُلاطَفة في التَّعليم والصَّبر على المُتعلِّم:

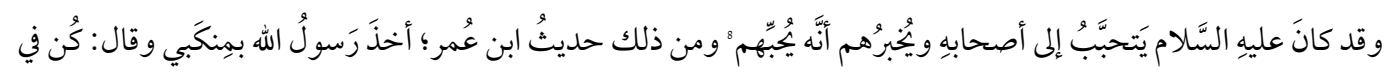

1 عبد الله ناصِح علوان، تَربية الأولادِ في الإسلام، 2: 737.

مسلم، الجامع الصَحيح، حَديث: 5.

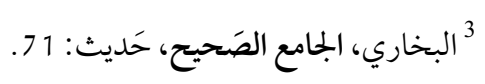

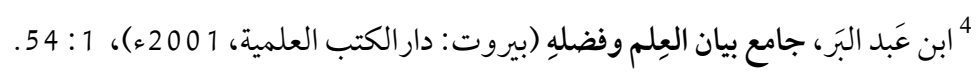

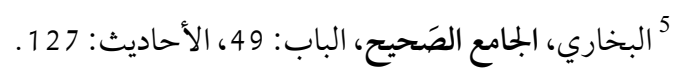

6 مُسلمِم، الجلامع الصَحيح، مُقدِّمة، باب: 3.

7 البخاري، الجامع الصَحيح، حَديث: 127.

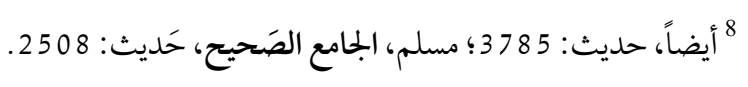




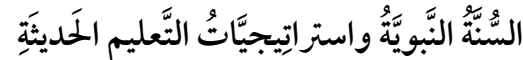

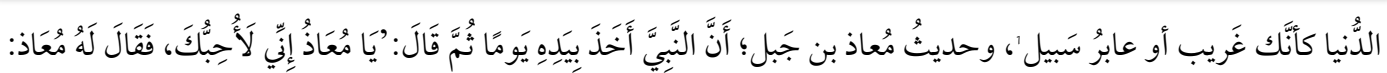

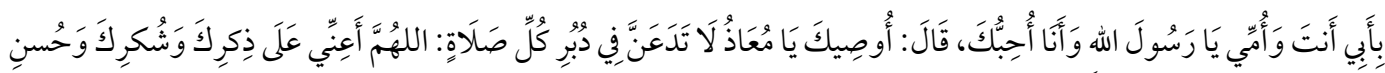

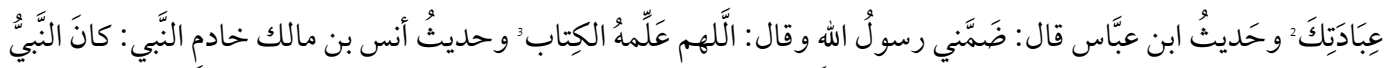

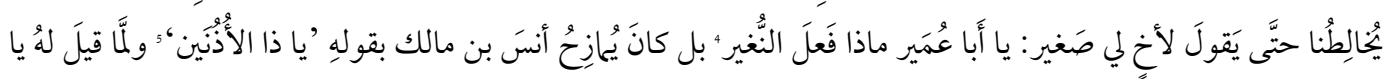

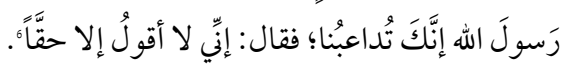

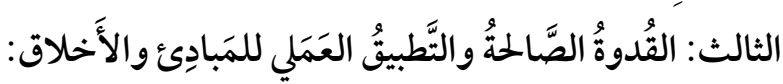

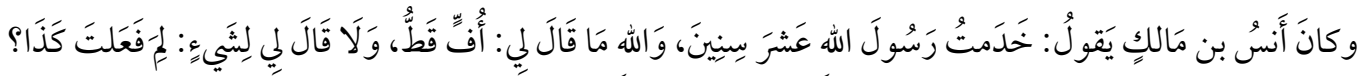

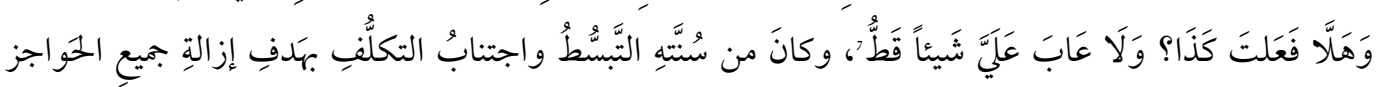

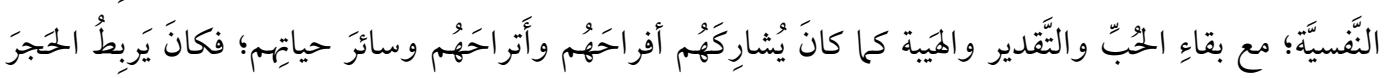

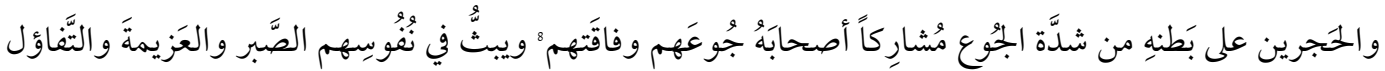

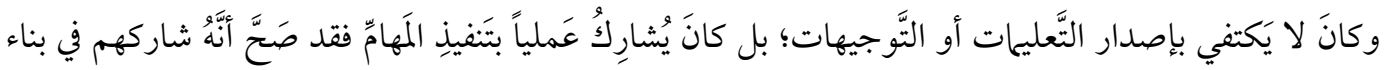

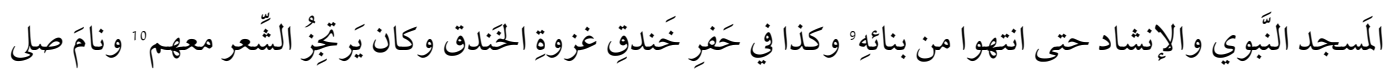

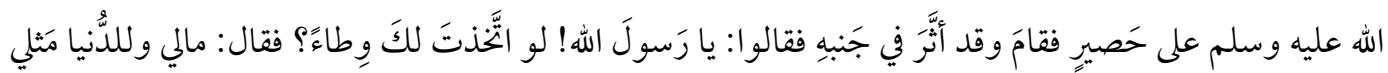

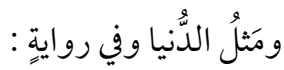

$$
\begin{aligned}
& \text { البخاري، الجامع الصَحيح، حديث: } \\
& \text { 2 أحمد بن حَنبل، المُسنَك، حَديث: } 22119 . \\
& \text { 3خخاري، الجامع الصَحيح، حديث: } 75 . \\
& \text { 4أيضاً، حديث: }
\end{aligned}
$$

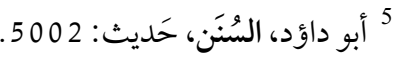

$$
\begin{aligned}
& \text { 6 أَمد بن حَنبل، المُسنَد، حَديث: } \\
& \text { 7 البخاري، الجامع الصَحيح، حديث: } 10 \text { 23؛ مسلم، الجامع الصَحيحُ، حَديث: } 2310 . \\
& \text { 8 التّّمذي، السُنَن، حديث : } 1372 \text { وقال: حديث غريب. } \\
& \text { 9 البخاري، الجامع الصَحيح، حديث: } 3932 . \\
& \text { 10 أيضاً، حديث، 2834؛ مسلم، الجامع الصَحيحُ، حَديث: } 1803 .
\end{aligned}
$$




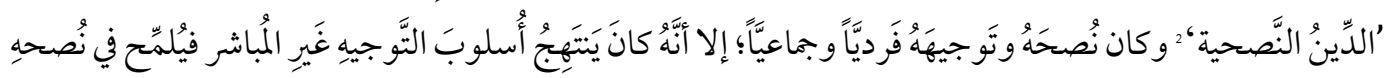

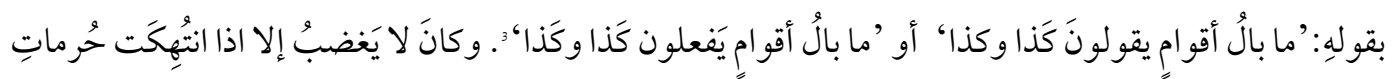

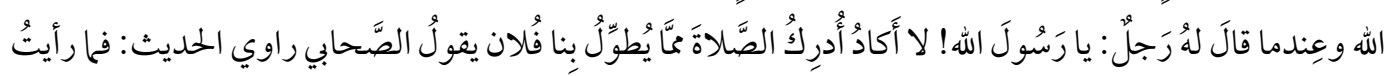

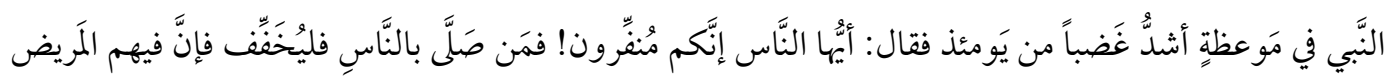

$$
\text { والضعيف وذا الحاجةُ4. }
$$

الخامس: استنَهاضُ المِمَم و الطَّاقات وتَنميةٌ الثِّقة بالنَّفس:

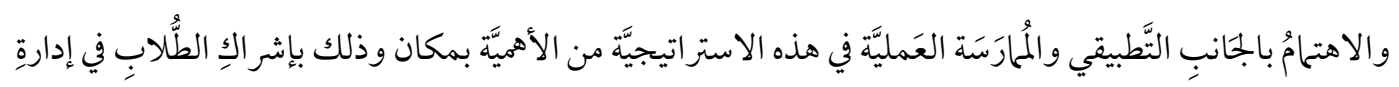
العَمليَّة التَّعليميَّة وتَنفيذهم مَشاريعَ وتَّاربَ عِلميَّة بأيديهم؛ وهو ما كان يفعلهُ رسولُ الله بمشاوَرَتِهِ لأصحابِ

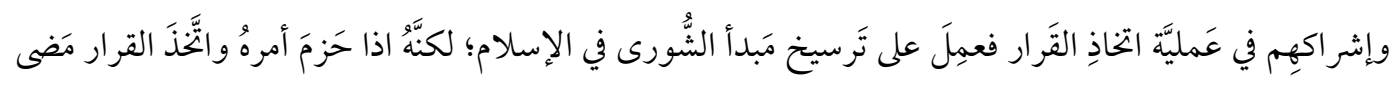

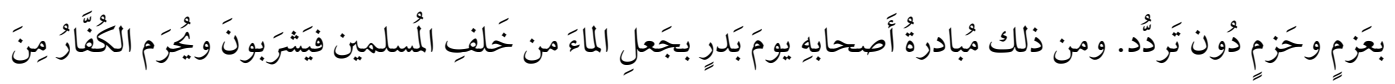

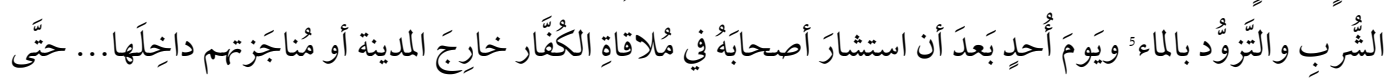

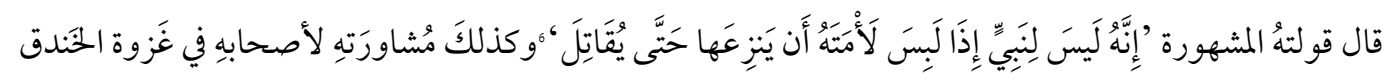

$$
\begin{aligned}
& \text { 1التِّرمذي، السُنَن، حديث : } 2377 \text { 2 أحمد بن حنبل، المُسنَد، الأحاديث: } 2744 . \\
& \text { 2² البخاري، الجامع الصَحيح، حديث: } 57 \text { ؛ مسلم، الجامع الصحيح، حديث: } 55 .
\end{aligned}
$$

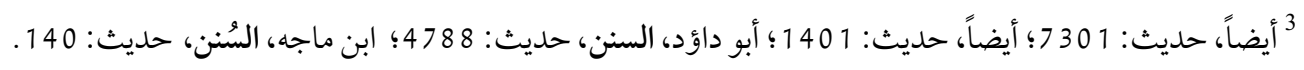

$$
\begin{aligned}
& \text { 4 البخاري، الجحامع الصَحيح ، حديث: 90؛ مسلم، الجامع الصحيح ، حديث: } 466 . \\
& \text { 5 الحاكم،حمد بن عبدالله، المُستَدرك على الصَّحيحن (بيروت: دار الكتب العلمية، 1990ء 19 ه)، حديث: } 5801 .
\end{aligned}
$$

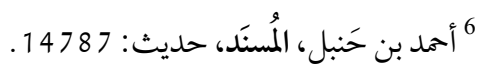




\section{السُّنَُّ النَّبويَّةُ واستراتِيجيَّاتُ التَّعليم الحَديثَةِّ}

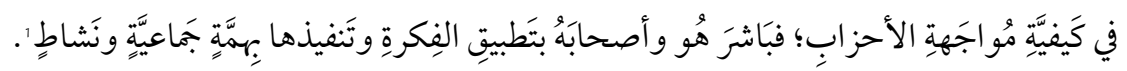
السادس: تَعليمُ الطَّلبةِ اتخاذَ القرارِ وإدارةَ المَوَ اقفِ الصَّعبة:

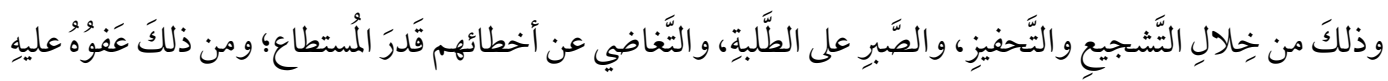

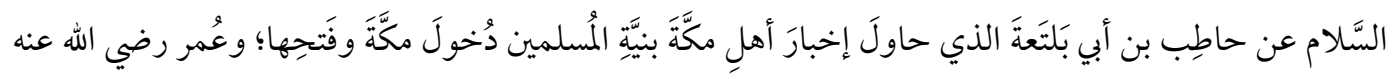

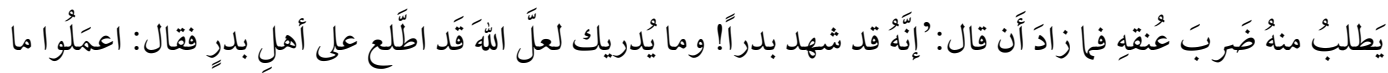

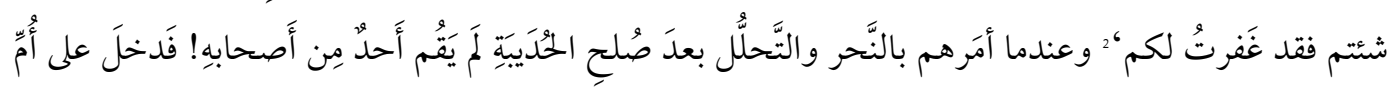

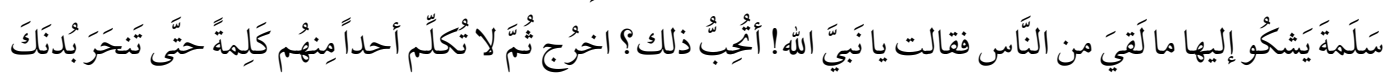

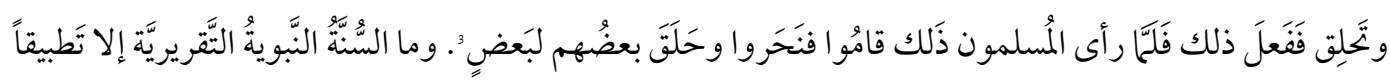

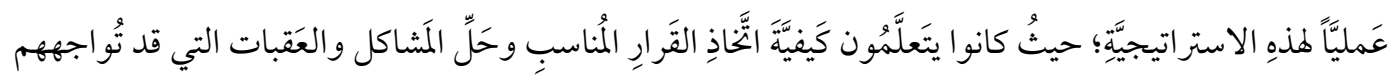

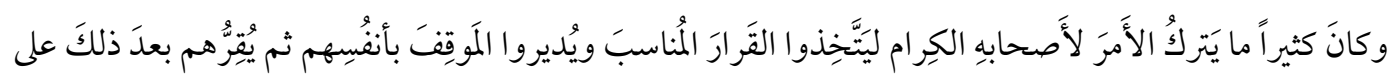

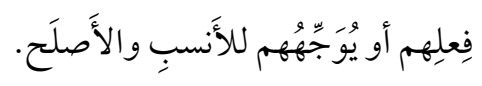

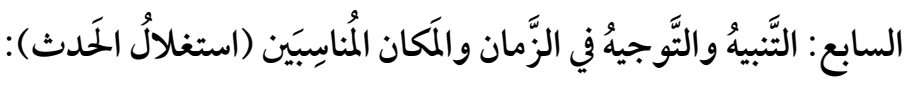

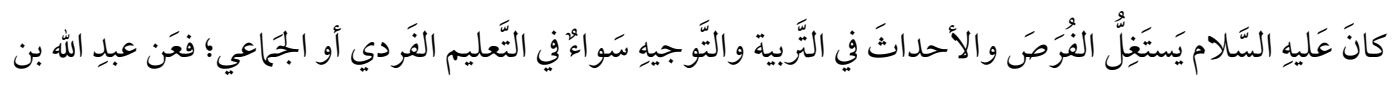

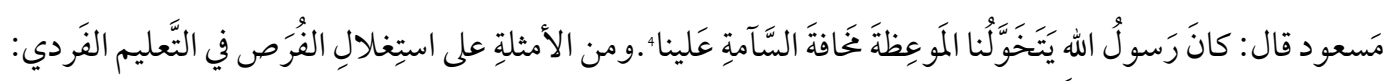

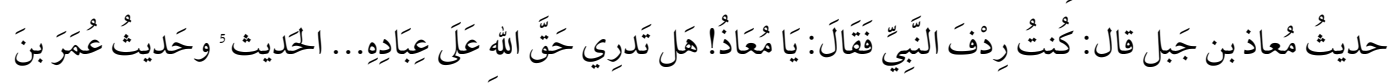

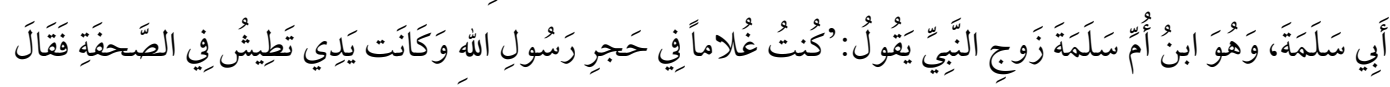

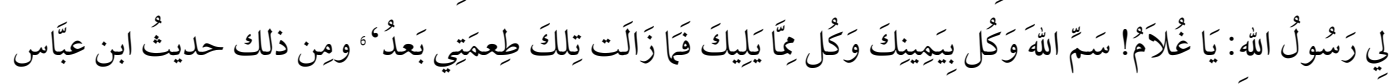

$$
\begin{aligned}
& \text { 1ابن حَجر، أحمد بن على، فَتح الباري شَرح صَحيح البُخاري (بيروت: دار المعرفة، 13790)، 7: } 393 . \\
& \text { 2² البخاري، الجامع الصَحيح، حديث: } 3007 .
\end{aligned}
$$

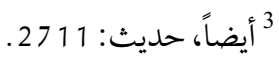

$$
\begin{aligned}
& \text { 4أيضاً، حديث: } 68 \text { ؛ مُسلم، الجامع الصَحيحُ، حديث: } 2821 . \\
& \text { 5 أيضاً، حديث: } 656 \text { 28 ؛ أيضاً، حديث: } 30 . \\
& \text { 6 أيضاً، حديث: أصنا، حديث: }
\end{aligned}
$$


إيقان: المجلد: 02 ، العدد:04: بو ، يونيو 2020ء

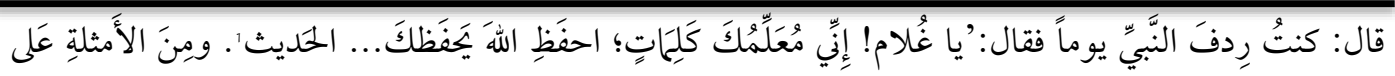

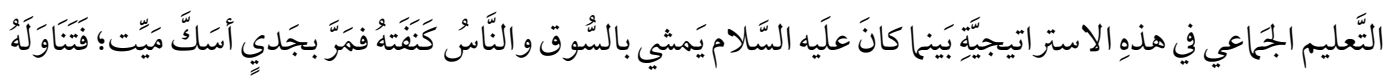

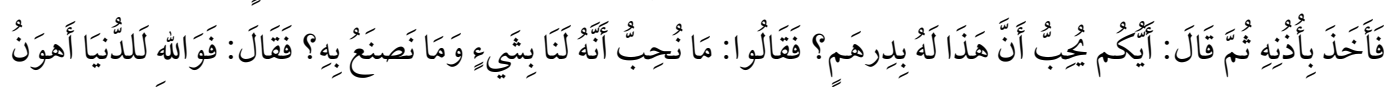

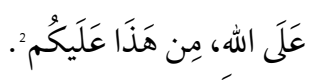

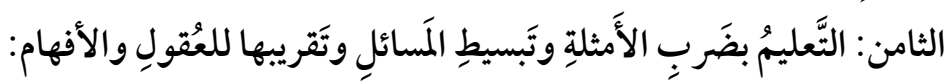

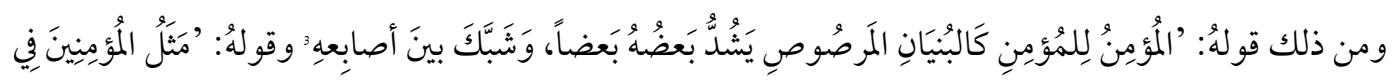

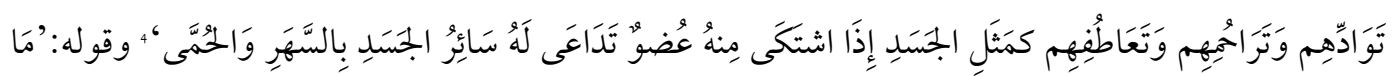

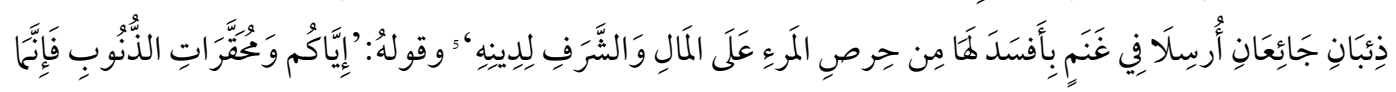

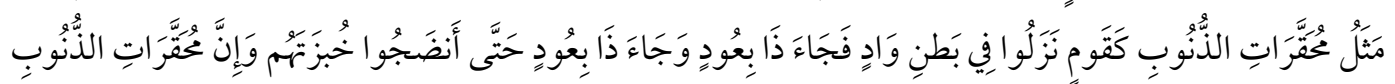

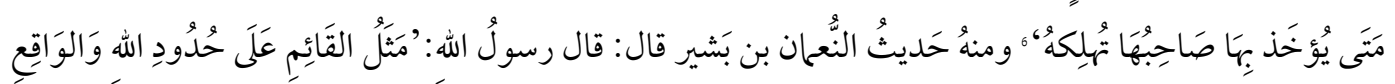

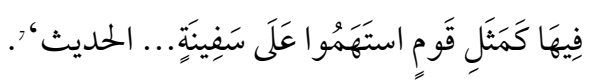

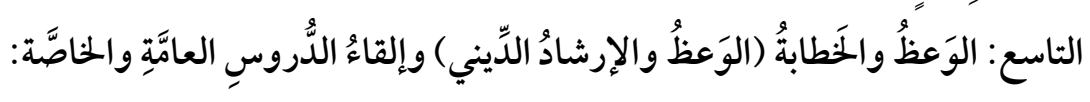

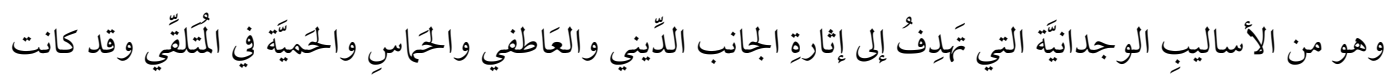

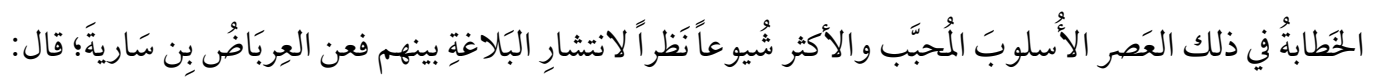

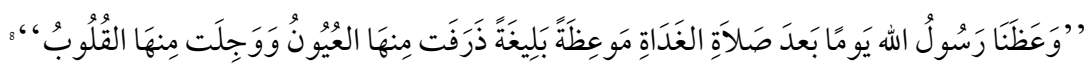

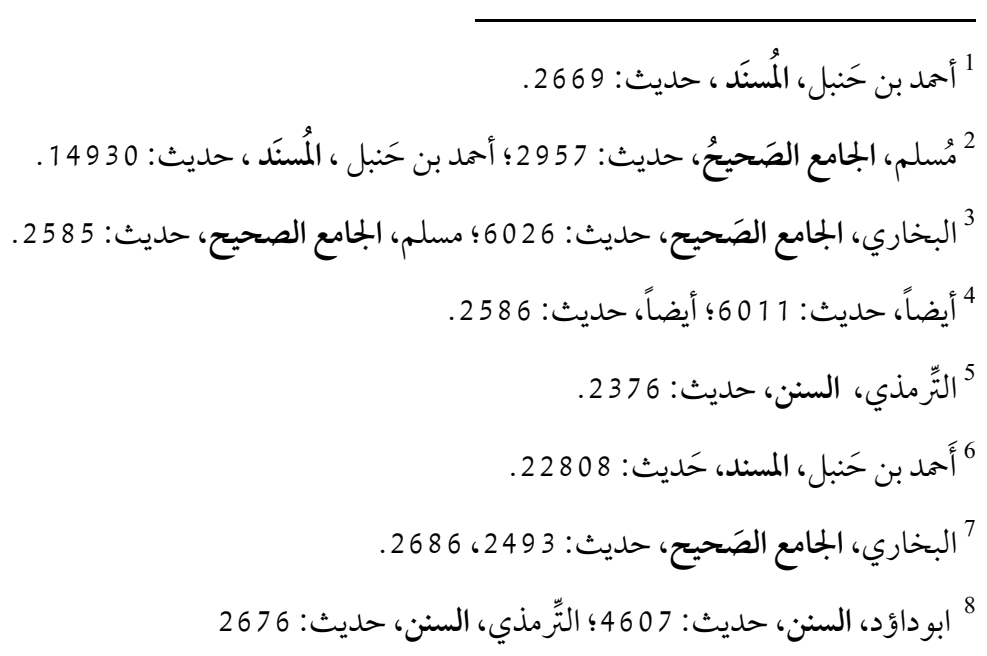




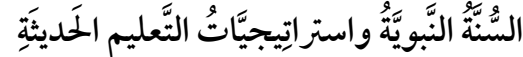

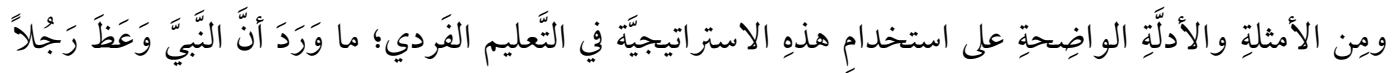

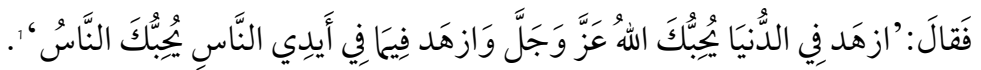

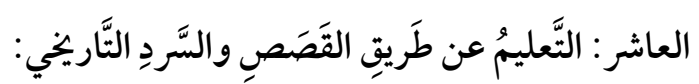

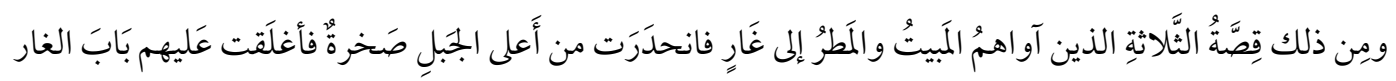

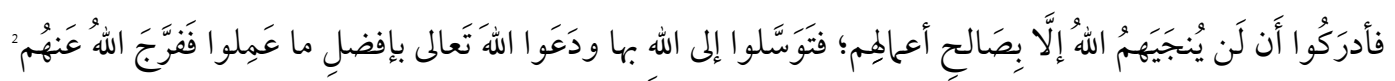

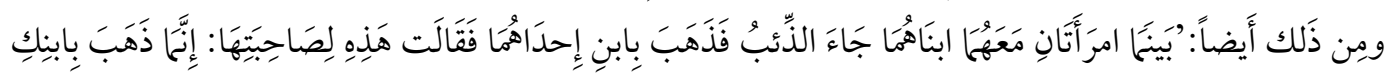

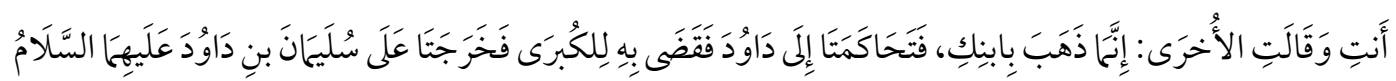

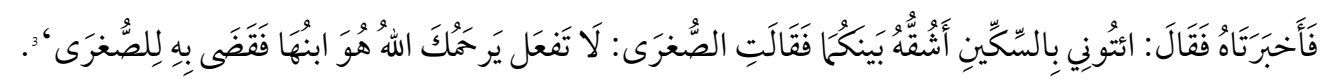

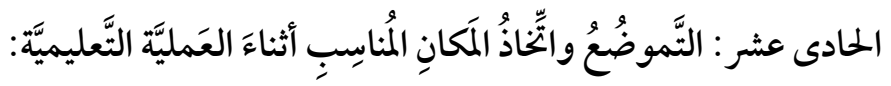

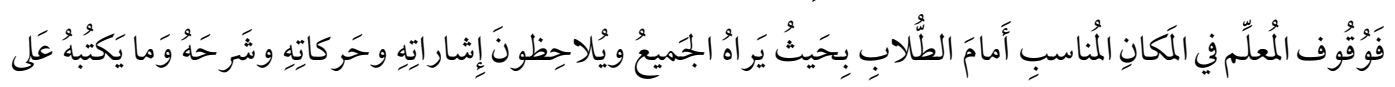

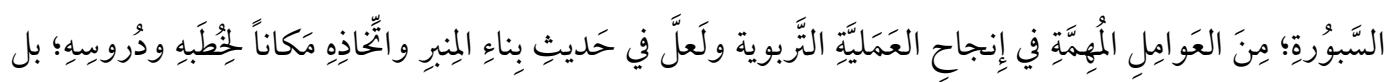

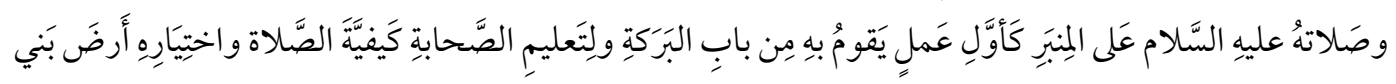

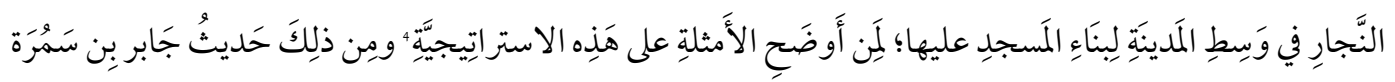

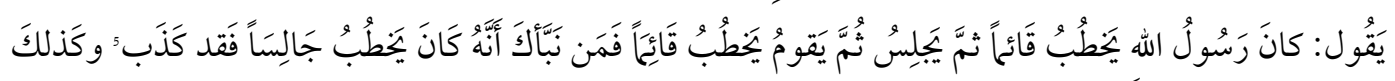

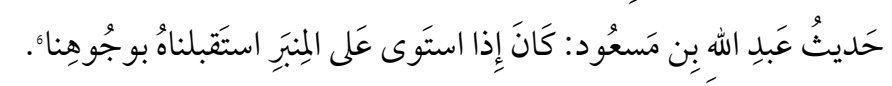

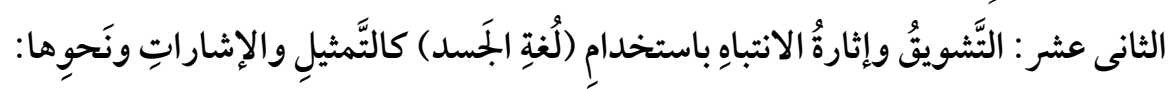

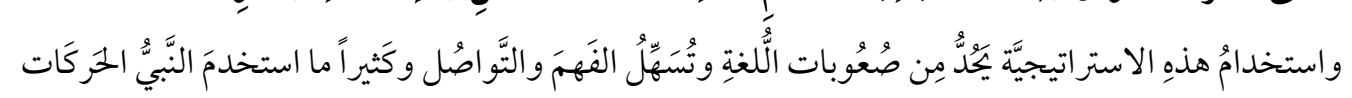

1 الحاكم، محمد بن عبدالله، المُستَدرَكُ على الصَّحيحين، حديث: 7873

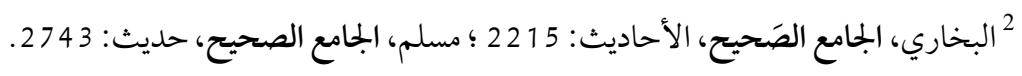

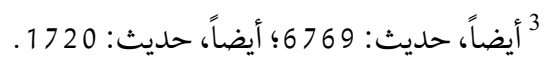

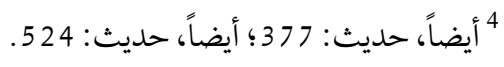
5 أيضاً، حديث:

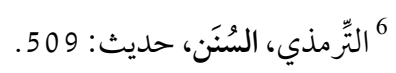




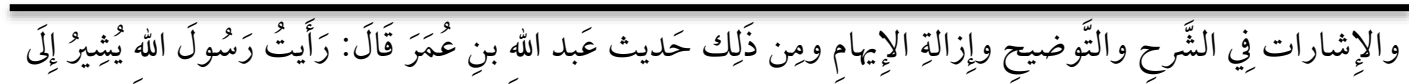

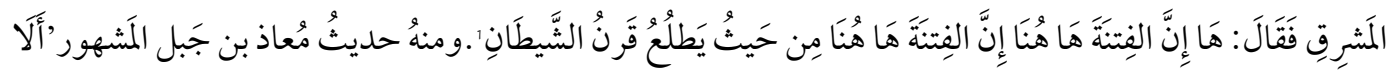

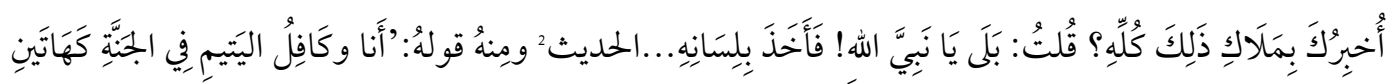

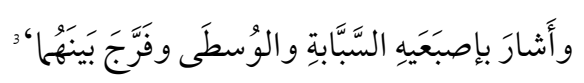

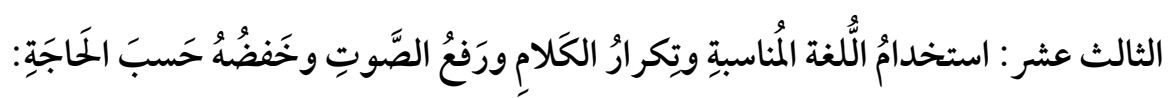

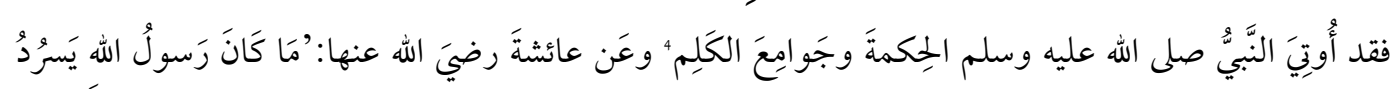

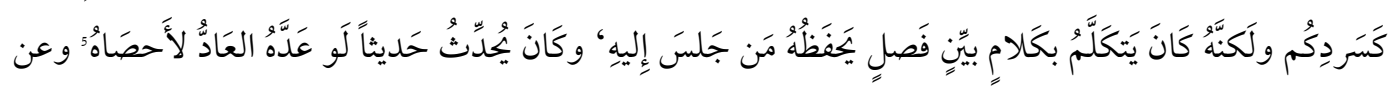

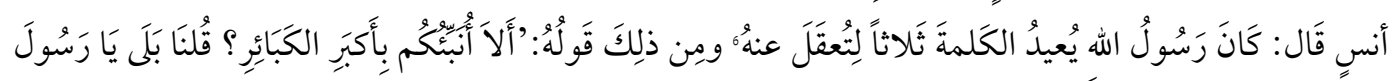

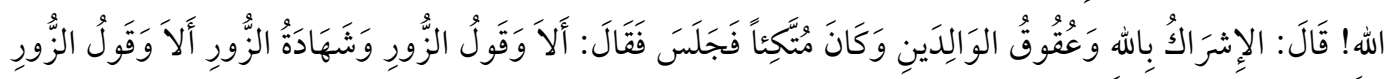

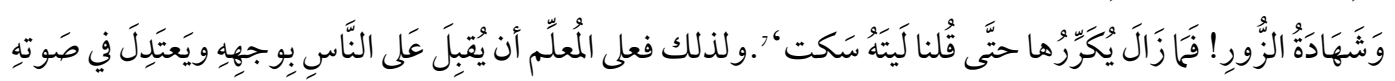

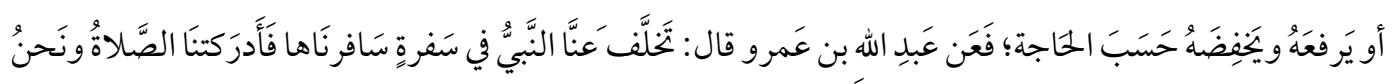

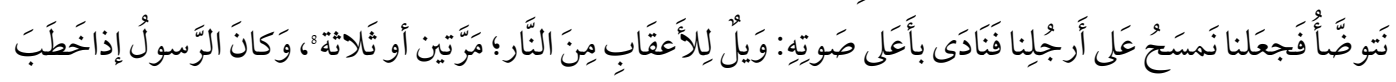

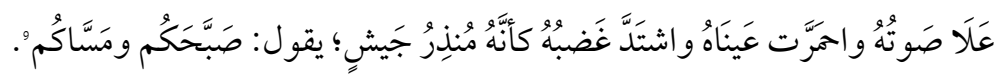

$$
\begin{aligned}
& \text { 1 البخاري، الجامع الصَحيح، حديث: 327 32 مسلم، الجامع الصحيح، حديث: } 2905 .
\end{aligned}
$$

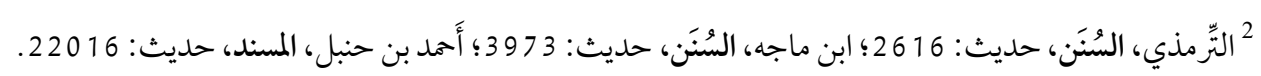

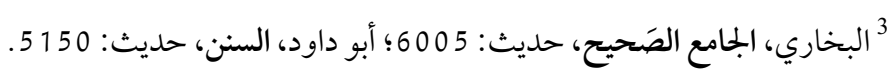

$$
\begin{aligned}
& \text { 4أيضاً، حديث: 2977، 297، 6998، 7013 701 أيضاً، حَديث: } 523 .
\end{aligned}
$$

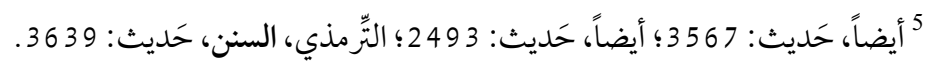

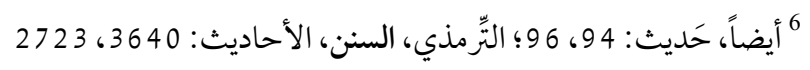

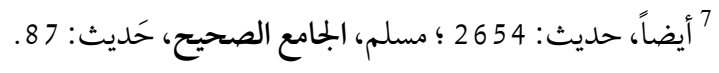

$$
\begin{aligned}
& \text { 8 أيضاً، حديث: } 60 \text { ؛ أيضاً، حَديث: } 240 . \\
& 9 \text { 9سلم، الجامع الصحيح، حَديث: } 867 .
\end{aligned}
$$




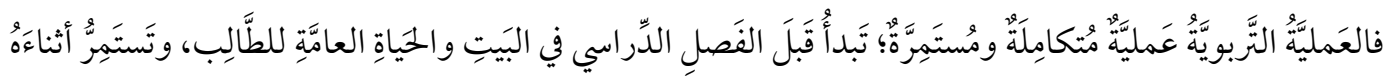

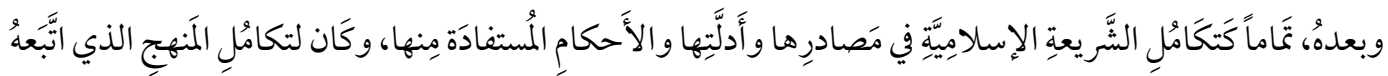

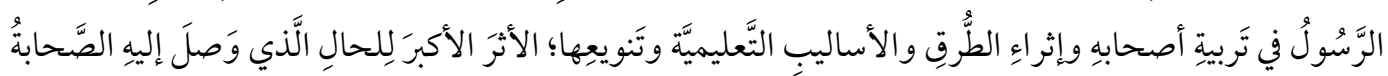

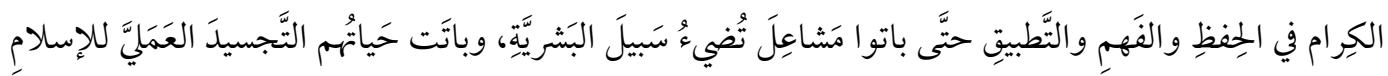

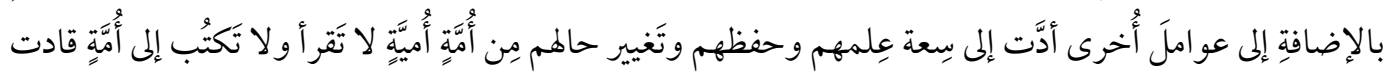

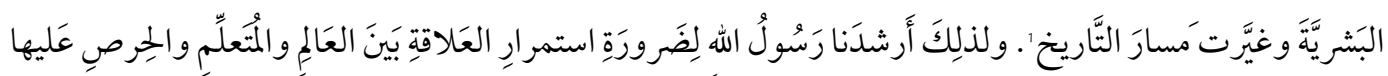

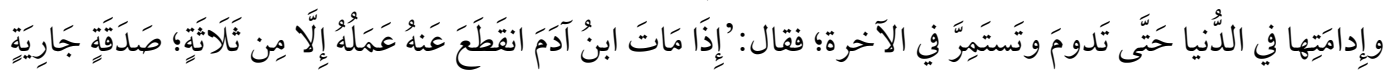

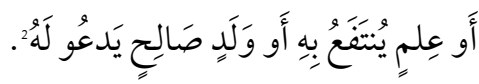

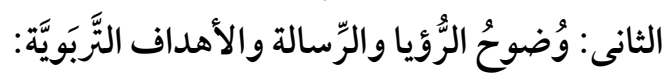

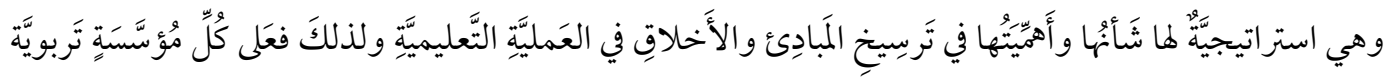

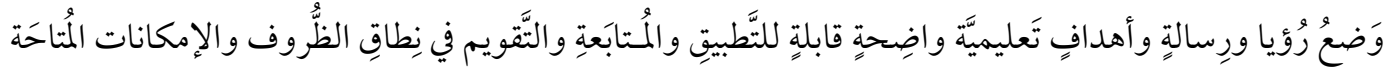

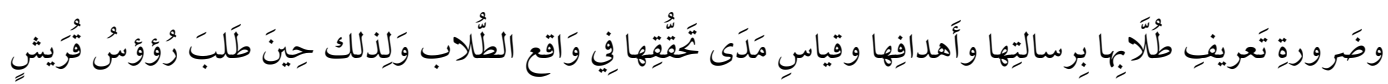

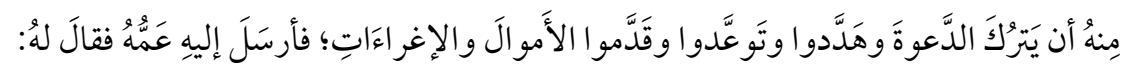

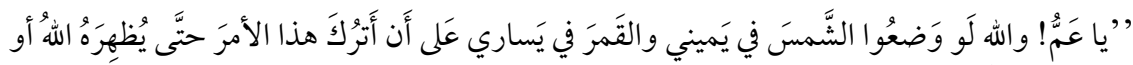

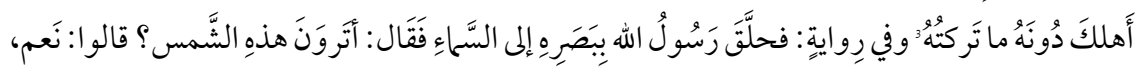

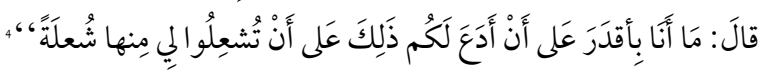

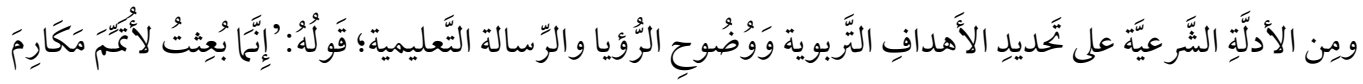

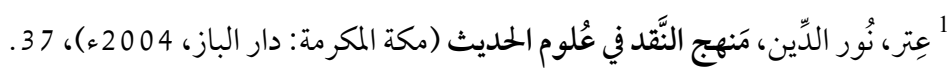

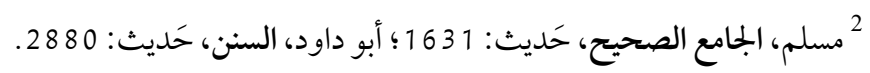

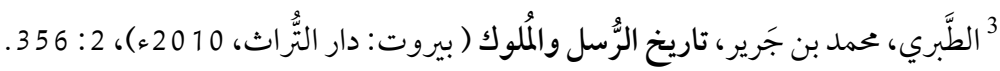

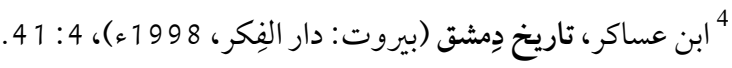


إيقان: المجلد: 02 ، العدد:04 ، يونيو 2020ء

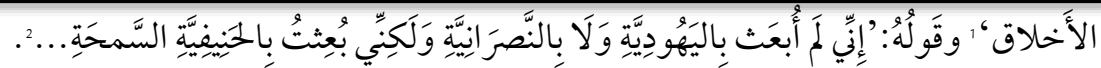

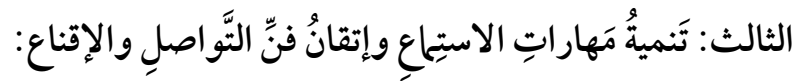

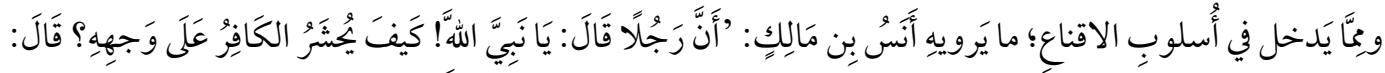

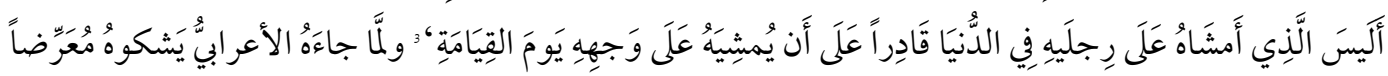

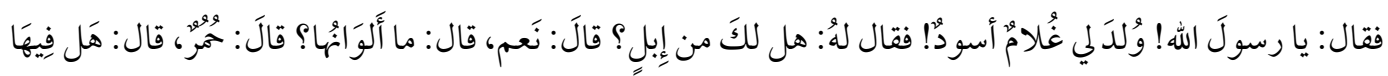

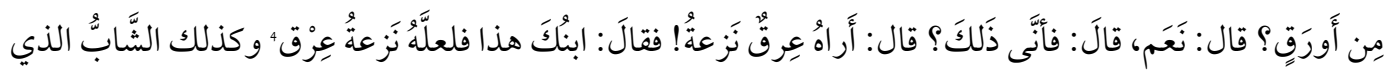

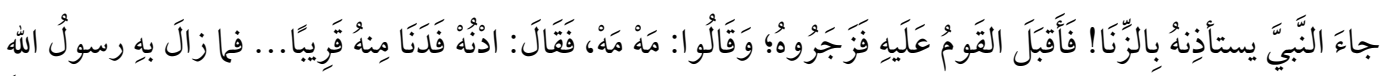

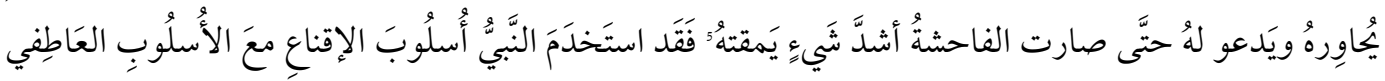

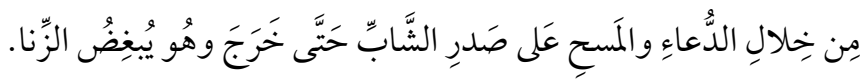

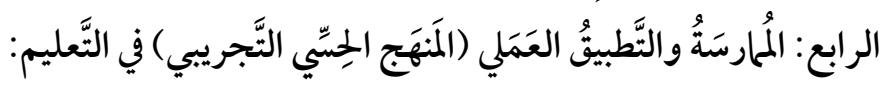

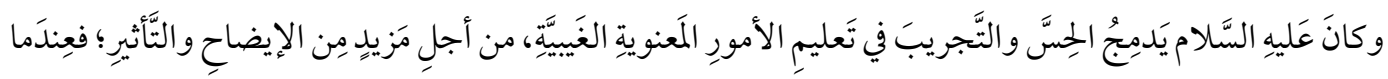

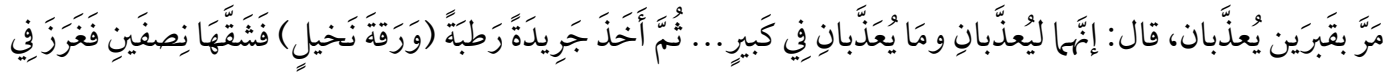

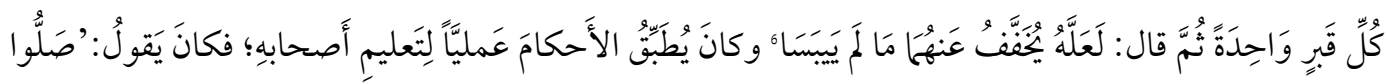

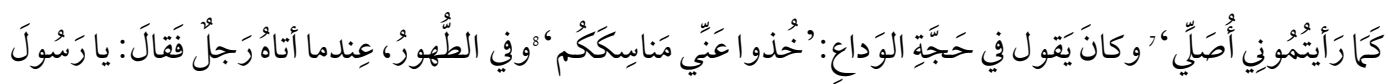

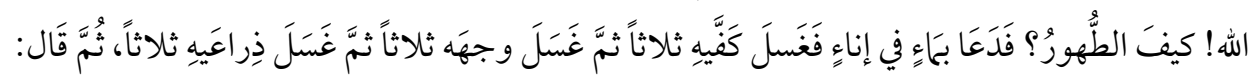

$$
\begin{aligned}
& \text { 1 البخاري، محمد بن إسماعيل، الأدَب المُفَرَد (الرياض: مكتبة دار العلم، 2003ء)، حديث : } 273 .
\end{aligned}
$$

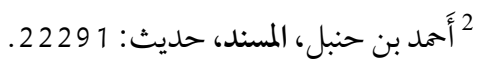

$$
\begin{aligned}
& \text { 3 البخاري، الجحامع الصَحيح، حديث: 4760؛ مسلم، الجحامع الصحيح، حديث: } 2806 . \\
& \text { 4أيضاً، حديث: 6847؛ أيضاً، حديث: } 1500 .
\end{aligned}
$$

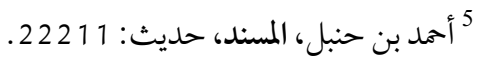

$$
\begin{aligned}
& \text { 6 البخاري، الجامع الصَحيح، حديث: 216؛ مسلم، الجامع الصحيح، حديث : } 292 . \\
& \text { 7 البخاري، الجامع الصَحيح، حديث: } 628 .
\end{aligned}
$$

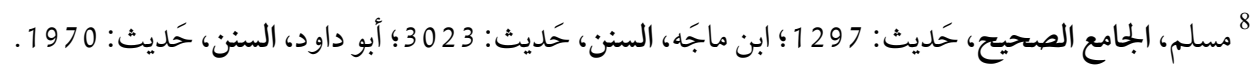




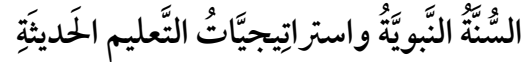

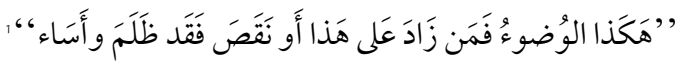

الخامس: التَّعليمُ عن طَريقِ الَّلَبِ المادفِ والأنَثِطَّة:

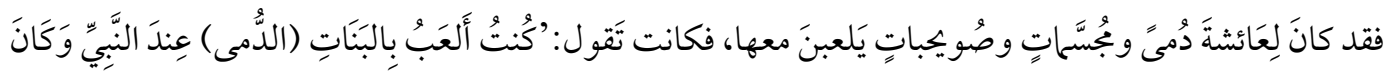

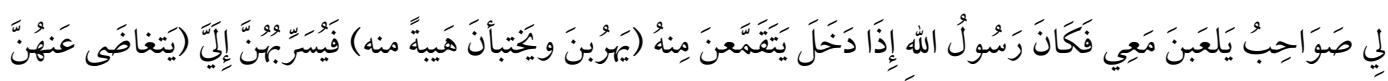

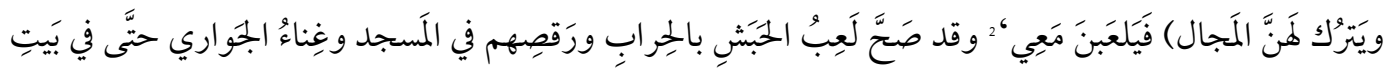

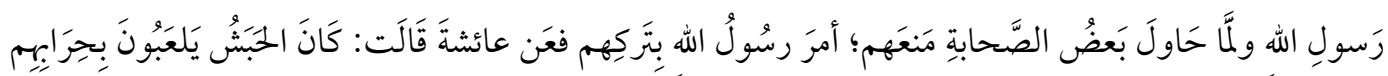

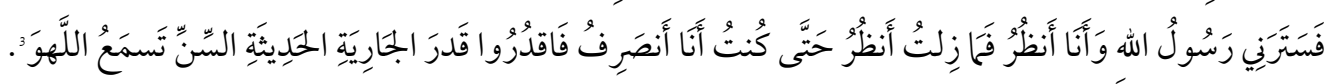

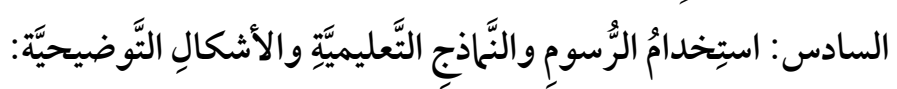

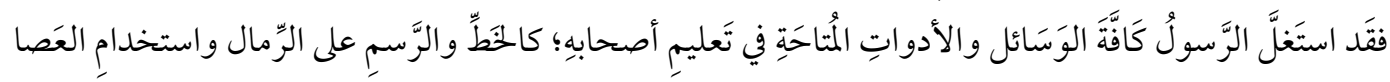

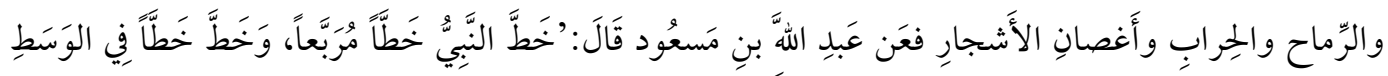

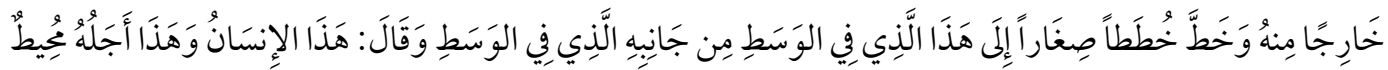

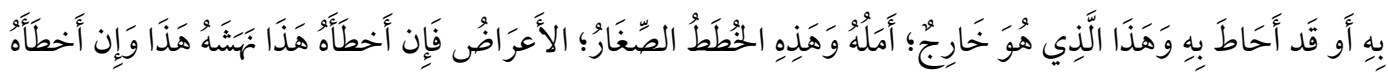

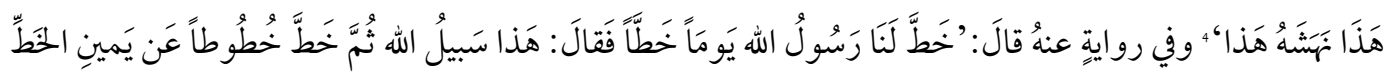

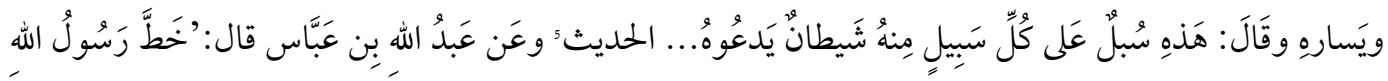

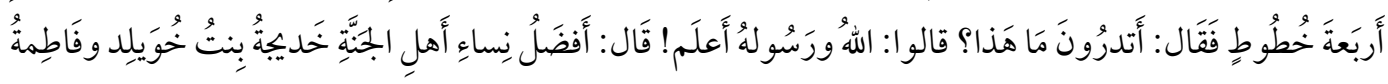

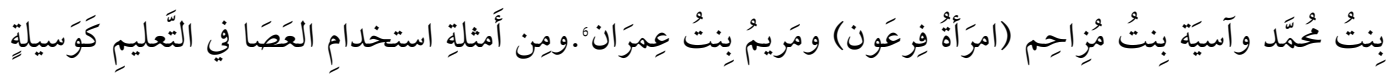

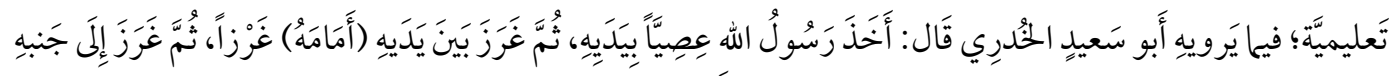

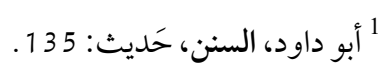

$$
\begin{aligned}
& \text { 22 البخاري، الجامع الصَحيح، حديث: } 6130 \text { 6ـ مسلم، الجامع الصحيح، حديث : } 2440 . \\
& \text { 3 أيضاً، حديث: 44 4؛ أيضاً، حديث: } 892 . \\
& \text { 4 مسلم، الجامع الصحيح، حديث: 64 64؛ أحمد بن حَنبل، المسند، حديث: 365 36؛ التّرّمذي، السنن، حديث: } 2454 .
\end{aligned}
$$

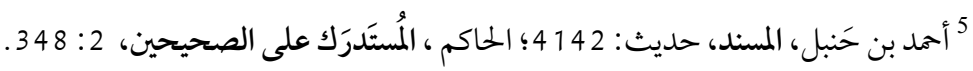

$$
\begin{aligned}
& \text { 6 أيضاً، حديث: } 2668 .
\end{aligned}
$$


إيقان: المجلد: 02 ، العدد:04 ، يونيو 2020ء

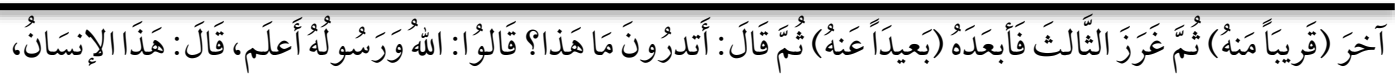

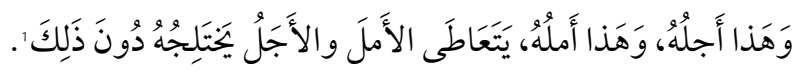

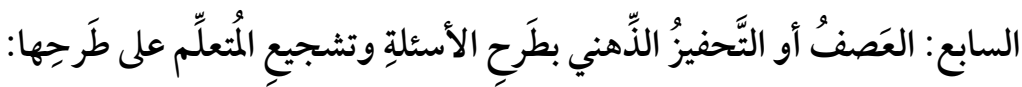

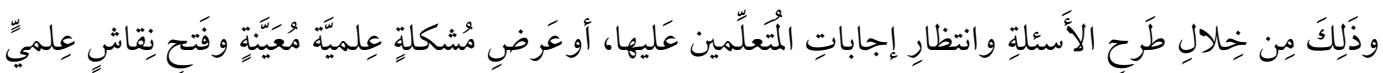

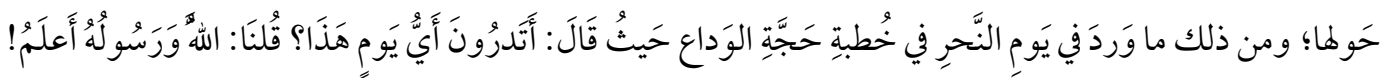

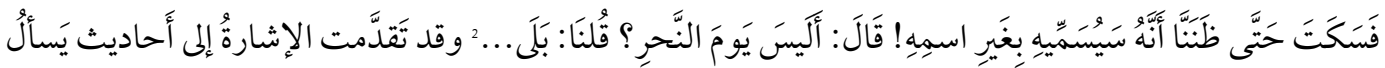

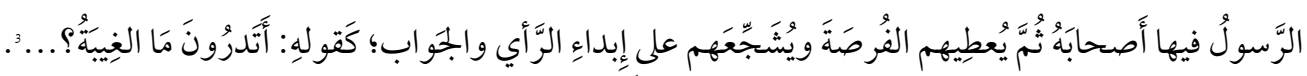
الثامن: التَّتجيعُ والتَّحفيز المَادِّي والمَعنوي:

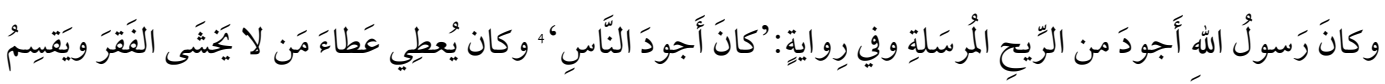

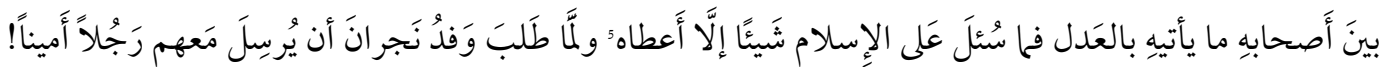

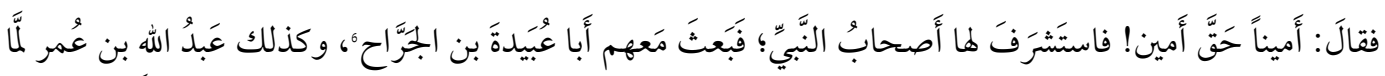

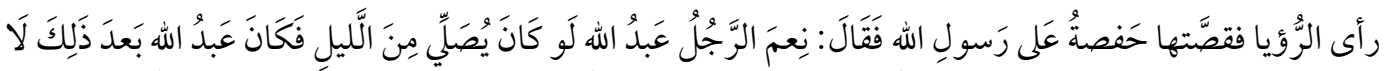

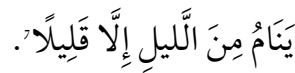

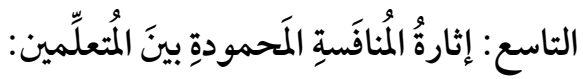

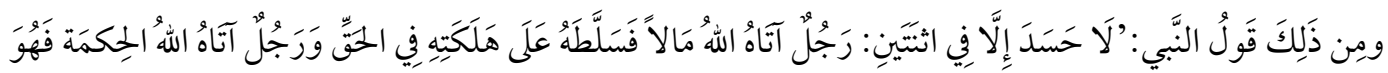

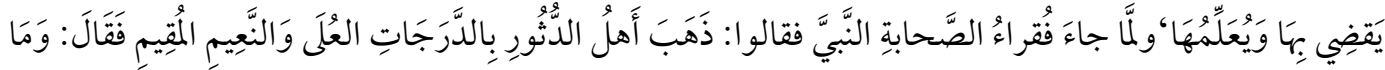

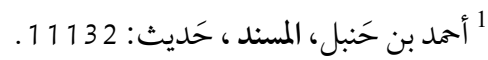

2 البخاري، الجامع الصَحيح، حديث: 1739 ؛ـ مسلم، الجامع الصحيح، حديث: 1679.

3سمبم، الجامع الصحيح، حديث: 2589

4أيضاً، حديث: 1902؛ أيضاً، حديث: 2308.

5 أحمد بن حَنبل، المسند، حديث: 2042.

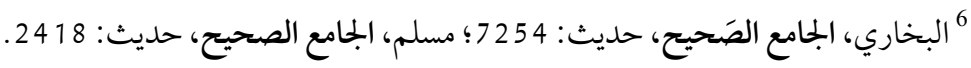
7أيضاً، حديث: 1121؛ أيضاً، حديث: 2478. 


\section{السُّنَُّ النَّبَويَّة واستراتِيجيَّاتُ التَّعليم الحَديثَةِّ}

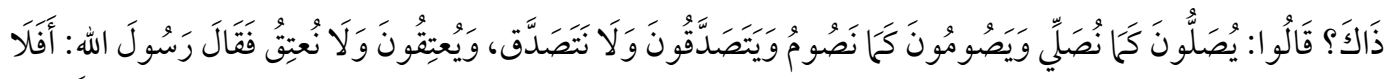

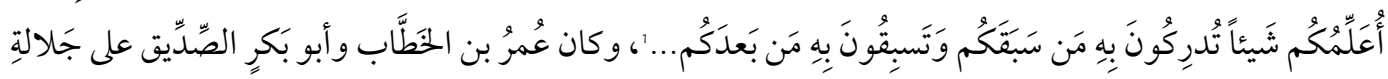

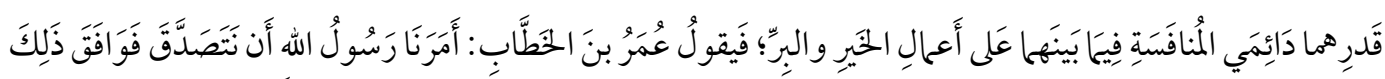

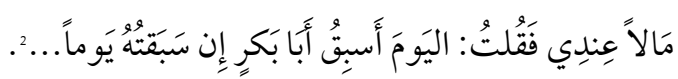

الخَاتيمّة: نتائجُج وتَوصيَّات:

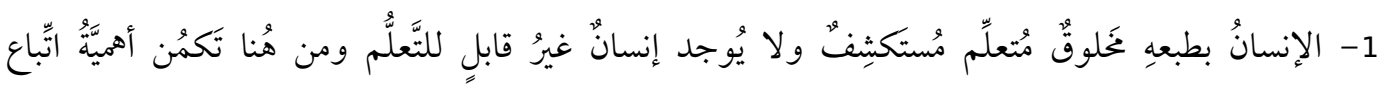

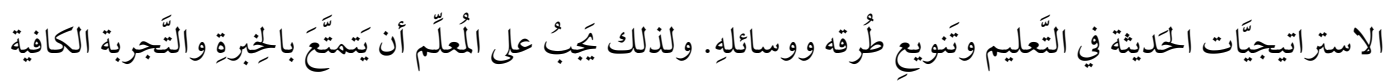

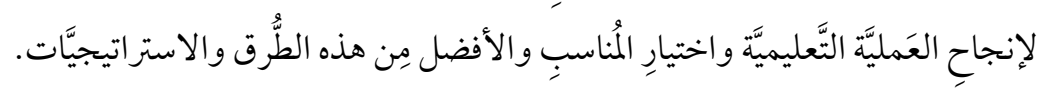

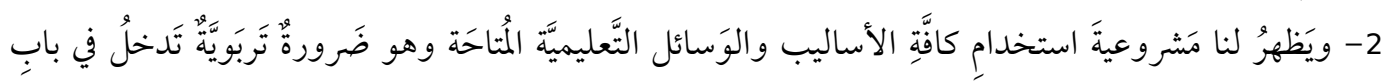

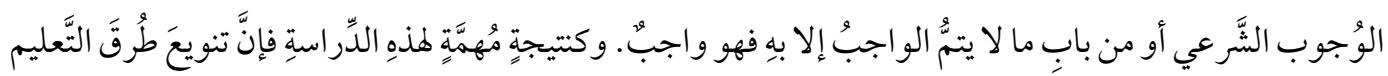

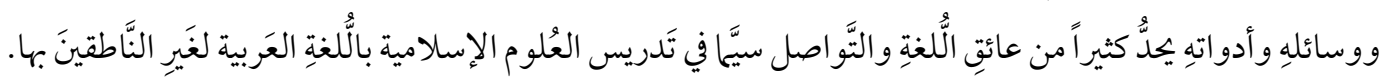

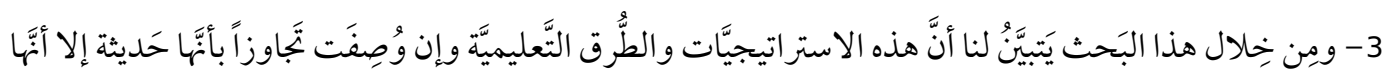

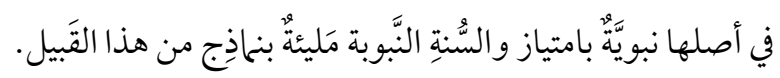

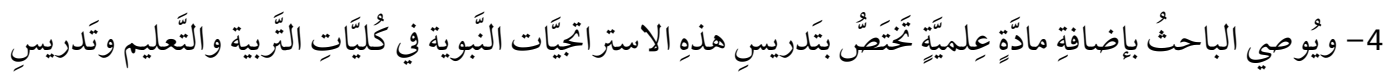

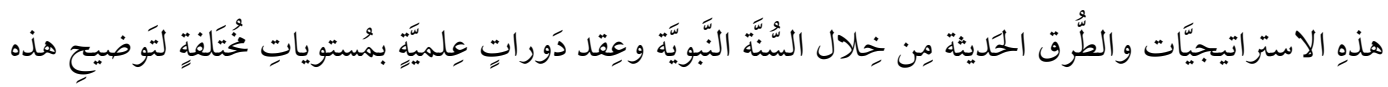
الكُنوز وإجلاءِ النُبارِ عنها.

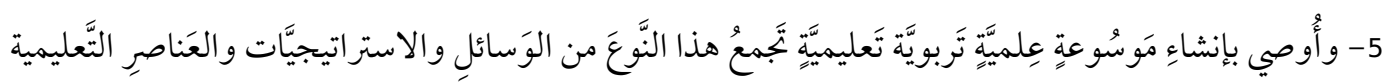

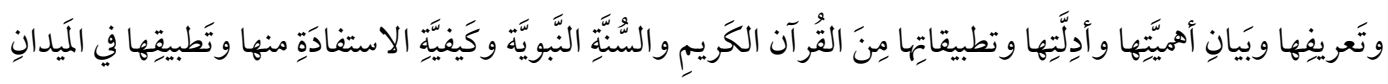

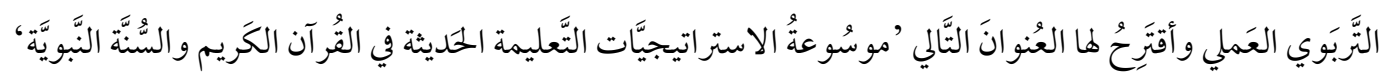
Under the terms and conditions of the Creative Commons Attribution (CC-BY) (http://creativecommons.org/licenses/by/4.0/)

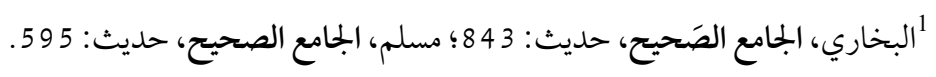

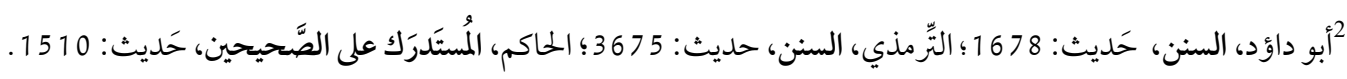

